\title{
Molecular mechanisms in therapy of acid-related diseases
}

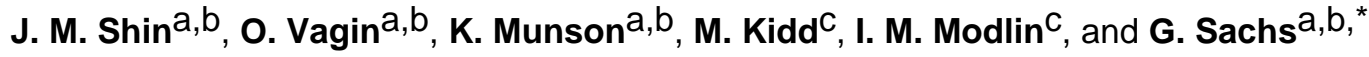 \\ a Department of Physiology, David Geffen School of Medicine, University of California at Los \\ Angeles, Los Angeles, California (USA) \\ b VA Greater Los Angeles Healthcare System, West LA Medical Center, 11301 Wilshire \\ Boulevard, Building 113, Los Angeles, California 90073 (USA), Fax: +310 3129478 \\ c Yale University School of Medicine, Department of Surgery, TMP202, 333 Cedar Street, New \\ Haven Connecticut 06520-8062 (USA)
}

\section{Abstract}

Inhibition of gastric acid secretion is the mainstay of the treatment of gastroesophageal reflux disease and peptic ulceration; therapies to inhibit acid are among the best-selling drugs worldwide. Highly effective agents targeting the histamine $\mathrm{H} 2$ receptor were first identified in the 1970s. These were followed by the development of irreversible inhibitors of the parietal cell hydrogenpotassium ATPase (the proton pump inhibitors) that inhibit acid secretion much more effectively. Reviewed here are the chemistry, biological targets and pharmacology of these drugs, with reference to their current and evolving clinical utilities. Future directions in the development of acid inhibitory drugs include modifications of current agents and the emergence of a novel class of agents, the acid pump antagonists.

\section{Keywords}

Gastric acid secretion; peptic ulcer; gastroesophageal reflux disease; proton pump inhibitors; pharmacology; H,K ATPase

\section{Introduction}

Peptic ulcer disease and gastroesophageal reflux disease (GERD) are common and important causes of morbidity and mortality. Indeed their impact on quality of life and economic productivity indices are considered to be in the same range as cardiac disease and cancer. In particular, sleep disturbance from nocturnal GERD - often unrecognized - has recently been determined to be a critical problem in the maintenance of overall well-being. Suppression of gastric acid secretion remains an integral part of the management of both GERD and peptic ulcer disease. Delineation of the mechanisms underlying gastric acid secretion either by identifying important receptors [1,2] or the acid pump [3-7] has facilitated the development of a targeted approach to therapy. In the present review, a history of the development of measures to suppress acid secretion will be provided. Since the proton pump per se is now regarded as the most important target, we shall present an analysis of the structure-function relationships of the gastric acid pump with emphasis on sites where drugs exert their action, discuss the mechanisms of proton pump inhibition and review how proton pump inhibitors (PPIs) are activated within parietal cells. Finally, we shall consider their current role in the

\footnotetext{
*Corresponding author: gsachs@ucla.edu.
} 
management of peptic ulcer disease and GERD and discuss new therapies that have been developed to address the problems with current therapy.

\section{Evolution of therapy for dyspepsia and ulcers}

It has been recognized for millennia that ingestion of antacids such as chalk $\left(\mathrm{CaCO}_{3}\right)$ that buffer gastric acid can alleviate the pain associated with peptic ulcer disease. However, the relief afforded by the neutralization of injurious gastric acid is only transient, and therefore more effective measures to raise gastric $\mathrm{pH}$, such as those designed to reduce gastric acid secretion, have been sought in more recent times.

The first drug shown to reduce gastric acid secretion was an extract of deadly nightshade, belladonna. The active principle in this extract is atropine, a non-selective muscarinic antagonist. Since there are five muscarinic receptors, widely distributed throughout the body, the use of atropine is associated with side effects, including dry mouth, difficulty in urination and dilation of the pupil with blurred vision, that render the treatment particularly bothersome. Subsequently, there considerable attention was given to the possibility of surgical treatment for peptic ulcers. At the end of the nineteenth century, total and partial gastrectomy was introduced in Vienna by Theodor Billroth [8]. Later, these procedures was replaced by complete vagotomy, partial vagotomy and, eventually, highly selective vagotomy. The latter operation was reasonably effective at controlling acid secretion by ablating muscarinic stimulation of acid secretion, and was also free of the side effects associated with atropine administration.

\section{Establishment of targets for suppression of acid secretion}

Elucidating the mechanisms of gastric acid secretion laid the groundwork for modern approaches to therapy. The chambered frog gastric mucosa and the fistula dog or everted dog flap models established that the major stimuli of acid secretion were the hormones acetylcholine, histamine and gastrin. Research then focused on developing antagonists to the receptors for these hormones.

\section{Receptors}

\section{Muscarinic agents}

Considerable effort was devoted to finding a more selective muscarinic antagonist than atropine. This culminated in the development of pirenzepine, a relatively selective M1 antagonist, although the parietal cell expresses an M3 receptor [9]. However, despite its effectiveness in healing peptic ulcers, this drug was still not free of side effects [10].

\section{Histamine Receptor Antagonists}

The histamine receptor antagonists (H2RAs) developed initially in the 1950s were effective against the vascular effects of histamine, but were of little value in the control of gastric acid secretion. Thus, the concept arose that there was more than one type of histamine receptor. A team led by James Black, working for the pharmaceutical company Smith Kline and French, discovered the first agent that selectively targeted the $\mathrm{H} 2$ receptor, burimamide [1]. Subsequently, metiamide and then finally cimetidine were introduced in 1977 [11]. Cimetidine represented the first anti-ulcer medication which was well tolerated. Several other H2RAs were then developed, such as ranitidine, famotidine and nizatidine. All were successful in accelerating the healing of peptic ulcers, but had to be given chronically to avoid ulcer recurrence (a problem in about $\sim 60 \%$ of patients when treatment was discontinued). Two other problems surfaced: first, these drugs were more effective in controlling nighttime acid secretion than day-time acid secretion, and their effectiveness was 
diminished by $\sim 50 \%$ after 1 week of therapy due to tolerance [12]. Moreover, these drugs were also relatively ineffective in treating GERD. Evidently, blocking only one of the parietal cell secretagogues was sub-optimal.

\section{Gastrin receptor antagonists}

Edkins initially identified a bioactive mucosal agent from the gastric antrum that stimulated gastric acid secretion in 1905 [13]. Identification of this peptide, subsequently termed gastrin, represented the confirmation of Bayliss and Starling's hypothesis of chemical messengers in the gut mucosa capable of activating other cells [13]. Excessive secretion of gastrin by a neuroendocrine cell neoplasm is responsible for the extreme acid hypersecretion of the Zollinger-Ellison syndrome. Milder elevations of plasma gastrin were also found to be associated with acid dysregulation in peptic ulcer disease, and subsequently demonstrated to be secondary to the Helicobacter pylori infection that underlies most peptic ulcer disease [14].

With the elucidation of the structure of gastrin, several peptide analogs of gastrin were synthesized, which could theoretically competitively inhibit gastrin-stimulated acid secretion [15]. However, these were not effective, and a more potent series of non-peptide compounds have been developed subsequently, though they are still not in clinical use [16]. It would be expected that their effectiveness might be similar to that of H2RAs.

Unexpectedly, administration of H2RAs was discovered to abolished gastrin but not cholinergic stimulation of acid secretion, indicating the action of gastrin was mediated by the release of histamine from neuroendocrine cells of the stomach and that muscarinic stimulation was by a different route [1]. These cells were initially thought to be mast cells, but later were recognized as the enterochromaffin-like cell (ECL) of the gastric fundic mucosa [17].

The acid pump-The demonstration in 1976 that gastric acid secretion was due to the action of a electro-neutral ATP-dependent hydrogen-potassium exchanger, the H,K ATPase [3], suggested that an inhibitor of the pump would be more effective in suppressing gastric acid secretion than a receptor antagonist, since proton secretion by the pump is the final step of acid secretion [18]. Accordingly, if inhibition of the pump were effective, hormonal stimulation of the parietal cell by whatever route could not increase gastric acid secretion.

\section{Proton pump inhibitors}

The discovery of inhibitors of the ATPase began with serendipity. A compound, timoprazole, had been developed in 1975 that inhibited acid secretion irrespective of the nature of the stimulus, whether it was ligands acting via extracellular receptors such as histamine or acetylcholine or the intracellular second messenger, cAMP. This compound, pyridylmethylsulfinyl benzimidazole was synthesized by Hassle AB, a Swedish drug company with an interest, like almost all other companies at that time, in developing a treatment for peptic ulcer disease. Its mechanism was not known but it resulted in thyrotoxicity and thymotoxicity in rats. The first polyclonal antibody developed against the gastric H,K ATPase showed immune reactivity with the thyroid and also with the thymus in addition to the stomach, and it was therefore natural to test timoprazole and a subsequent compound, picoprazole, against the H,K ATPase [17]. It was found that in the absence of acid transport by the ATPase, the compound was relatively ineffective, as was its successor, picoprazole, synthesized in 1977. However, when the pump was transporting acid, the compounds did inhibit acid secretion after a lag phase [19]. Based on examination of the structure of the compounds and the characteristics of the inhibitory effect (i.e. a requirement for the presence of acid and the lag phase), it was deduced that these two compounds were 
acid-activated pro-drugs [18]. Subsequently, omeprazole was synthesized and became the first drug of this class to be introduced into clinical use, in 1989. Omeprazole was followed by lansoprazole, pantoprazole, rabeprazole and more recently, by the S-enantiomer of omeprazole. All of these drugs inhibit the gastric H,K ATPase by covalently binding to it by forming disulfides, and therefore the duration of their effect is longer than expected from their levels in the blood [20]. This class of drug, the PPIs, is currently the standard treatment for acid-related diseases. Although sharing a similar mechanism of action, there are subtle chemical differences between the PPIs that affect the precise mechanism by which they inhibit the pump. This may result in clinical differences in their effectiveness.

\section{Acid pump antagonists}

An alternative to PPIs is another class of drugs, the reversible $\mathrm{K}^{+}$-competitive acid pump antagonists (APAs or P-CABs) exemplified by the imidazo[1,2 $\alpha]$ pyridine, $\mathrm{SCH} 28080$ $[21,22]$. As for PPIs, these compounds depend for their activity on achieving an effective concentration in the parietal cell canaliculus, but since they do not require acid activation and inhibit the pump in the $\mathrm{E}_{2} \mathrm{P}$ conformation, the onset of their action is predicted to be more rapid than that of PPIs but of shorter duration. Several variants of these compounds have been synthesized and some are in late phases of clinical development.

\section{Structure-function relationship of the gastric $\mathrm{H}, \mathrm{K}$ ATPase}

\section{Primary structure}

After the elucidation of the primary amino acid sequence in the rat [23], the amino acid sequence of the hog [24], rabbit [25] and human [26] $\alpha$ subunits containing the catalytic site was determined. These subunits are $\sim 1033$ or 1034 amino acids in length in all species and they are $98 \%$ homologous with each other. Functional studies demonstrated that ATP catalyzed an electro-neutral exchange of $\mathrm{H}$ for $\mathrm{K}$, with a stoichiometry of $2 \mathrm{H} / 2 \mathrm{~K} / \mathrm{ATP}$ at $\mathrm{pH}$ 6.1 that fell to $1 \mathrm{H} / 1 \mathrm{~K} / \mathrm{ATP}$ as luminal $\mathrm{pH}$ fell to $<3.0[27,28]$. Examination of the sequence of the catalytic subunit revealed that it was highly homologous to the Na,K ATPases ( 75\%) and less so to the SERCA Ca ATPase (25\%) [29]. This family of ion transport ATPases with 10 transmembrane segments in their catalytic subunit transports small cations and is defined as the $\mathrm{P}_{2}$ type ATPases, indicating that they are phosphorylated and dephosphorylated during their catalytic cycle. The $\mathrm{P}_{1}$ type family has eight transmembrane segments and transports the larger alkaline earth metals such as $\mathrm{Cu}^{2+}$.

\section{Catalytic cycle}

Studies in the 1970s examining the determinants of phosphorylation and $\mathrm{K}^{+}$-dependent phosphorylation showed that the gastric $\mathrm{H}, \mathrm{K}$ ATPase had remarkable similarity in its biochemically defined catalytic cycle to that developed earlier for the homologous $\mathrm{Na}, \mathrm{K}$ ATPase [30]. This has been complicated recently by the demonstration that this enzyme turns over as an out-of-phase oligomeric heterodimer. Both the gastric H,K ATPase and $\mathrm{Na}, \mathrm{K}$ ATPases are fully assembled as an oligomeric heterodimer during biosynthesis in the endoplasmic reticulum and the functional form of the enzyme is an $\left[\alpha_{2} \beta_{2}\right]$ heterodimeric oligomer [31-33]. Details of this dimeric cycle defined by the stoichiometry of phosphorylation and inhibitor binding are shown in Figure 1.

\section{Secondary structure}

The gastric ATPase is an integral membrane protein. The $\alpha$ subunit contains 10 transmembrane segments with the $\mathrm{N}$ and $\mathrm{C}$ termini located in the cytoplasm [34], whereas the $\beta$ subunit of each enzyme has a single transmembrane segment with the $\mathrm{N}$ terminus located in the cytoplasm and the majority of the protein ending in the $\mathrm{C}$ terminus located exoplasmically. 
In the $\alpha$ subunit of all $\mathrm{P}_{2}$ type ATPases, there is a cluster of intramembranal carboxylic amino acids located in the middle of the transmembrane segments TM4, TM5, TM6 and TM8 that contain the ion-binding domain as shown by site-directed mutagenesis $[35,36]$. In the gastric H,K ATPase, there is a unique lysine located in the fifth transmembrane segment. This lysine substitutes for a serine present in the Na,K ATPase isoforms. Site-directed mutagenesis of residues of the Na,K ATPases [36,37], the SR Ca ATPase [38] and the H,K ATPase $[27,35,39]$ showed that the ion-binding domain and other features of the gastric ATPase were similar to the $\mathrm{Na}, \mathrm{K}$ and SERCA Ca ATPases.

The $\beta$ subunit was shown to be 291 amino acids in length containing six or seven $\mathrm{N}$-linked glycosylation sites [40-42]. The Na,K ATPases also have a $\beta$ subunit. One of the three isoforms of this pump, $\beta_{2}$, is most homologous to the $\beta$ subunit of the gastric H,K ATPase. Both the gastric $\beta$ and $\beta_{2}$ have six to eight glycosylation sites, whereas the $\beta_{1}$ or $\beta_{3}$ isoforms of the $\mathrm{Na}, \mathrm{K}$ ATPase have only three glycosylation sites [43]. The presence of a large number of glycosylation sites apparently results in sorting of the pump to the apical membrane in epithelia. The other prominent mammalian $\mathrm{P}_{2}$ type ATPases, the Ca ATPases, lack a $\beta$ subunit.

\section{Tertiary structure}

The development of methods to produce crystal structures of the SERCA ATPase at high resolution by Toyoshima and colleagues revolutionized understanding of the conformational changes during the catalytic cycle of these enzymes [44-46]. Using the crystal structure of the SERCA Ca ATPase in different conformations as a template, computer-generated homology modeling and site-directed mutagenesis resulted in not only an expanded picture of the ion transport mechanism of the gastric ATPase but also gave insight as to how the covalently binding PPIs and the $\mathrm{K}^{+}$-competitive APAs inhibit the pump. Since high resolution crystal structures of the $\mathrm{Na}, \mathrm{Kor} \mathrm{H}, \mathrm{K}$ ATPase have yet to be described, the exact location of the $\beta$ subunit is not known. It is thought that there is close interaction on the luminal surface with the entry of TM8 into the membrane domain $[47,48]$ and that perhaps the membrane domain of the $\beta$ subunit is interdigitated between TM9 and TM10 [49].

Given that the $\mathrm{Na}, \mathrm{K}$ and $\mathrm{Ca}$ ATPases that extrude the cations $\mathrm{Na}^{+}$and $\mathrm{Ca}^{2+}$ generally share the same carboxylic acids with the ion binding site of the H,K ATPase that have a presumed $\mathrm{pK}_{\mathrm{a}}$ between 3.0 and 4.0, how does this pump extrude protons at $\mathrm{pH} 1.0$, at a 100- to a 1000fold higher energy state relative to the presumed carboxylate $\mathrm{pK}_{\mathrm{a}} \mathrm{s}$ in the ion-binding domain of the gastric acid pump?

As illustrated in Figure 2, this depends on displacement of one of the bound hydroniums in the membrane ion-binding domain by movement of the $\mathrm{R}^{-\mathrm{NH}_{3}}{ }^{+}$(ammonium) group of lysine 791 with rotation of a sector of TM5 into the hydronium-binding site in the transition from $\mathrm{E}_{1} \mathrm{P}$ to $\mathrm{E}_{2} \mathrm{P}$ with, therefore, exposure of this $\mathrm{H} 2$ site toward the lumen. This ammonium group of the lysine residue will have high affinity compared to the $\mathrm{H}_{3} \mathrm{O}^{+}$, due to stabilization of the hydrogen bonding of the $-\mathrm{R}^{-\mathrm{NH}_{3}}{ }^{+}$of lysine 791 compared to $\mathrm{H}_{3} \mathrm{O}^{+}$in the $\mathrm{H} 2$ site. This results in displacement of the hydronium outward with, therefore, acid secretion. The entry of $\mathrm{K}^{+}$as a focal positive charge moves glutamyl 795 and 820 to allow release of lysine 791 back first towards, the $\mathrm{E} \cdot \mathrm{K}$ occluded conformation [27,50]. Its binding in the $\mathrm{E} \cdot \mathrm{K}$ occluded form is followed by displacement of the $\mathrm{K}^{+}$to generate the $\mathrm{E}_{1} \mathrm{~K}$ conformation enabling return of $\mathrm{K}^{+}$to the cytoplasm.

The overall general conformational changes of the enzyme are illustrated in Figure 3. Emphasis is placed on changes occurring in the cytoplasmic domain as the enzyme moves from an $E_{1}$ to an $E_{2}$ configuration following binding of $\mathrm{MgATP}$ and phosphorylation. The crystal structure has shown that the cytoplasmic domain is divided into three sectors named 
the $\mathrm{N}$ (nucleotide binding) domain, the $\mathrm{A}$ (actuator) domain and the $\mathrm{P}$ (phosphorylation) domain. Movements induced by ion and ATP binding in these domains are transmitted to the membrane domain to catalyze the ion displacements shown in Figure 2. The large changes in conformation in the cytoplasmic domain probably account for the finding that the enzyme functions as an out-of-phase oligomeric heterodimer [32]. Thus when one heterodimer is in the E1 form, the other is obligated to be in the E2 from. This has been most clearly demonstrated by measuring the stoichiometry of ATP binding, acid-stable phosphorylation and binding of APAs or PPIs.

The E1 form of the enzyme allows access to the ion-inding domain from the cytoplasmic surface and following binding of ATP with two Mg ions, one to stabilize the $\alpha \beta$ orientation to the first two phosphates of the nucleotide and the second, in proximity of the acceptor aspartyl residue, to allow transfer of the $\gamma$ phosphate to the catalytic subunit of the protein $[46,27]$ and initiate the change of conformation from the $\mathrm{E}_{1}$ form to the $\mathrm{E}_{1} \mathrm{P}$ conformer with the ion sites binding the hydronium ions. This is followed by conversion to the $\mathrm{E}_{2} \mathrm{P}$ form where the proton is released outward and $\mathrm{K}$ binds from the luminal surface following the path shown in Figure 2. A notable feature of the luminal face of this structure in the $E_{2}$ form is the presence of a luminal vestibule bounded by TM4, TM5 and TM6 and the connecting exoplasmic loops between TM3-TM4 and TM5-TM6 containing cysteine 813 as part of the loop between TM5 and TM6 (Fig. 3, arrow). This vestibule would be a natural exit and entry point for transported cations and would also provide access to the different classes of inhibitors of the gastric H,K ATPase and is illustrated in the model of Figures 2 and 3.

In summary, the catalytic subunit of the ATPase undergoes ATP and ion binding-dependent conformational changes during a cycle of phosphorylation and K-dependent

dephosphorylation, so that protons are transported outward and potassium inward in an obligatory electro-neutral exchange. The luminal exit and entry pathways for the ions provide a natural accession target for inhibitory drugs, be they PPIs or APAs.

\section{Chemistry of the PPIs \\ Structure of different PPIs}

There are several drugs of the proton pump inhibitor class on the market or approaching the market as shown in Figure 4.

\section{Activation of the PPIs}

With the realization that these compounds are weak bases with a $\mathrm{pK}_{\mathrm{a}}$ between $\sim 4.0$ (omeprazole, lansoprazole, pantoprazole) and 5.0 (rabeprazole), it was clear that they would accumulate in the acidic space of the secretory canaliculus of the stimulated parietal cell. This acid space-dependent concentration of the PPIs is their first important property that determines their therapeutic index giving a concentration at the luminal surface of the pump that is about 1000 -fold that in the blood.

The second vital step is $\mathrm{pH}$-dependent conversion from the accumulated prodrug to the activated species that is a highly reactive thiophilic reagent. This means that protonation of these compounds is required for their activation to form disulfides with cysteines of the $\mathrm{H}, \mathrm{K}$ ATPase. The order of acid stability is tenatoprazole $>$ pantoprazole $>$ omeprazole $>$ lansoprazole > rabeprazole. Earlier work with omeprazole suggested that the key protonated site was the $\mathrm{N}$ of the pyridine moiety but this would not explain the different rates of activation of the different PPIs. When the rate of conversion of different compounds was measured as a function of $\mathrm{pH}$ using $\mathrm{UV}$ absorbance beginning at a relatively neutral $\mathrm{pH}$, rather than at $\mathrm{pH} 2.0$ in the presence of a large excess of mercaptoethanol, it was found that the $\mathrm{pH}$ dependence of activation reflected protonation of the benzimidazole or pyrido- 
benzimidazole moiety [51]. The chemical reaction pathway for acid activation of the PPIs is shown in Figure 5.

To determine protonation of the pyridine nitrogen as compared to the benzimidazole nitrogen, the rate of activation of the PPIs was slowed to measure the reaction rate. This was achieved by methylation of one of the benzimidazole nitrogens of, for example, lansoprazole, thus allowing measurement or calculation of both $\mathrm{pK}_{\mathrm{a}} \mathrm{s}$ of the various PPIs.

Table 1 shows the two $\mathrm{pK}_{\mathrm{a}} \mathrm{s}$ of all the clinically available PPIs of Figure 4, showing the correspondence between the second $\mathrm{pK}_{\mathrm{a}}$ and the rate of activation. Rabeprazole has a high $\mathrm{pK}_{\mathrm{a}} 1$ that, by increasing the nucleophilicity of the pyridine $\mathrm{N}$, increases the rate of activation more than expected from the $\mathrm{pK}_{\mathrm{a}} 2$. The first column shows actual measurements and the second column $\mathrm{pK}_{\mathrm{a}} 2$ values that were estimated by calculation from the effect of $\mathrm{N}$ methylation of the benzimidazole of lansoprazole and by adding the protonated pyridinylmethylsulfinyl effect $(-0.73)$ to the 2-methylsulfinyl-1- $H$-benzimidazole $\mathrm{pK}_{\mathrm{a}}$ or to the other benzimidazole derivatives such as 2-methylsufinyl-5-methoxy- $1 \mathrm{H}$-imidazo[4,5$b$ ]pyridine (tenatoprazole). These $\mathrm{pKa}$ values predict that lansoprazole and omeprazole will be more rapidly converted to the active drug than either pantoprazole or tenatoprazole, and this property may account for the binding of the latter two drugs at cysteine 822 .

The actual inhibitory form of these prodrugs is somewhat controversial. In acidic solution, the form that is isolated is on the bottom left of Figure 5 prior to reaction with one or more cysteines accessible from the luminal surface of the enzyme, a tetracyclic sulfenamide. This was assumed for many years to be the actual active form of the drug, but more recent data suggest that it is the precursor of the sulfenamide, the hydrated sulfenic acid on the right above the enzyme reaction step that is the reactive species.

To explain the reaction with cysteine 813 or cysteine 321 without reaction with cysteine 822 , the likely first step is binding of the prodrug protonated on the pyridine part of the compound to the vestibule with cysteine 813 at its apex. With acid transport by the ATPase, the second proton is added and then the compound can be activated to the sulfenic acid. If this occurs rapidly, as for omeprazole or lansoprazole, reaction with cysteine 813 or also 321 takes place, and no drug can access cysteine 822. However, if the activation is delayed, the drug can access cysteine 822 before activation to the sulfenic acid, and then when activated, both cysteine 813 and 822 are derivatized, as has been shown when comparing the cysteines reacting with omeprazole, lansoprazole to those reacting with pantoprazole or tenatoprazole [52].

\section{Biology of PPIs}

PPIs are prodrugs, effective only after diprotonation as discussed above. After accumulation in the stimulated secretory canaliculus of the parietal cell and binding to the ATPase, the second protonation occurs and they are then activated to form the thiophilic drug that reacts with luminally accessed cysteines on the pump. It follows that the presence of acid secretion is necessary for their action. Hence it is recommended that they be given $\sim 30 \mathrm{~min}$ after a meal to ensure that the pump is active. It is also necessary to protect them from gastric acid prior to absorption. Consequently, they are all formulated with an acid-resistant coating that does not dissolve until $\mathrm{pH} \sim 5.0$, to allow access to the duodenum for absorption without destruction by gastric acid. With the exception of tenatoprazole, their half-life in blood varies between 60 and $90 \mathrm{~min}$, but because they bind to the pump covalently, their half-life of inhibition of gastric acid secretion is substantially longer than their half-life in blood. 


\section{Binding sites of PPIs}

The sites of reaction of the different PPIs on the enzyme differs according to the particular PPI. However, all PPIs react with cysteine 813 in the loop between TM5 and TM6 fixing the enzyme in the $E_{2}$ configuration. This cysteine as well as cysteines 321 and 822 are on the direct path from and to the ion-binding site as illustrated in Figures 2 and 3.

Omeprazole reacts with cysteine 813 and 892 , the latter being peripheral to the ion transport domain [53], and lansoprazole with cysteine 813 and cysteine 321, these being in the luminal vestibule [54], whereas pantoprazole and tenatoprazole react with cysteines 813 and $822[52,55,56]$. The reaction with cysteine 822 confers a rather special property to the covalently inhibited enzyme, namely irreversibility to reducing agents in vitro and in vivo. The binding sites for pantoprazole are shown in Figure 6 at cysteine 813, as for all the PPIs, and cysteine 822 which is a particular property of pantoprazole and tenatoprazole.

\section{Restoration of acid secretion after PPI inhibition}

The PPIs are inactive in their native form and are rapidly metabolized by the liver. They are remarkably free of significant adverse effects due to three factors: their ability to accumulate selectively in the highly acidic space of the stimulated secretory canaliculus of the parietal cell because of the $\mathrm{pK}_{\mathrm{a}}$ of the pyridine group of the PPIs, their formation of the reactive cationic (hence relatively membrane impermeable) sulfenic acid on the pump itself, and the requirement for a $\mathrm{pH}<2.5$ for a significant rate of activation.

These properties confer a very large therapeutic index, but they also cause a delay in suppression of the pump's activity. Since PPIs require stimulation of gastric acid secretion, they are more effective when administered shortly after a meal. Because they have a relatively short half-life and not all pumps are activated, it takes about 3 days to reach steady-state inhibition of acid secretion, since a balance is struck between covalent inhibition of active pumps, subsequent stimulation of inactive pumps after the drug has been eliminated from the blood and de novo synthesis of new pumps. The pump protein has a half-life of about $54 \mathrm{~h}$ in the rat (and probably in humans), thus about $20 \%$ new pumps are synthesized over $24 \mathrm{~h}$ and it may be that there is greater pump synthesis at night than during the day. Also, bedtime administration will not add to inhibition of nocturnal acid breakthrough, since the drug will have disappeared by the time nighttime acid secretion is evident.

Assuming that about $70 \%$ of pumps are activated by breakfast and that the PPI is given 3060 min afterward, it can be calculated that steady-state inhibition on once-a-day dosage is about $66 \%$ of maximal acid output. Increasing the dose has virtually no effect once optimal dosage has been reached, but increasing dose frequency has some effect. Thus, a morning dose and evening dose after meals results in about $80 \%$ inhibition of maximal acid output.

Until the tertiary structure of the pump was predicted based on homology to the Ca ATPase, the effect of binding of the drug to cysteine 822 and the direct reversibility of PPI inhibition was not examined. A prelude to this analysis of reversibility was evident in measurement of the half-time of pump protein biosynthesis in rats treated for 7 days with omeprazole $(54 \mathrm{~h}$ in untreated and treated rats) and the half-time of restoration of ATPase activity (15 h) suggesting a more rapid recovery of ATPase activity and acid secretion than if only de novo biosynthesis was responsible for restoration of ATPase activity [57]. In other experiments, the halftime of restoration of acid secretion in omeprazole-treated rats was $20 \mathrm{~h}[58,59]$. Analysis of the rate of restoration of acid secretion in humans following omeprazole suggested that the half-time was $24 \mathrm{~h}$ whereas after pantoprazole it was $46 \mathrm{~h}$. Apparently, only the latter drug gave a rate of recovery compatible with restoration of acid secretion entirely from pump turnover $[60,61]$. 
Experiments were conducted in rats to further investigate the problem. The animals were stimulated maximally by histamine and a large dose of radio-labeled omeprazole or pantoprazole administered intravenously. The gastric ATPase was isolated from stomachs removed at different times after drug administration (1-24 h). Using quantitative Western blots, it was possible to determine the stoichiometry of labeling, and by measuring acid secretion it was ascertained that about $90 \%$ inhibition had occurred after $1 \mathrm{~h}$. Then the isolated enzyme was treated with the natural reducing agent, glutathione, which has a concentration of about $3 \mathrm{mM}$ in the parietal cell.

As shown in the upper panel of Figure 7, incubation of the inhibited ATPase with glutathione resulted in a different rate of loss of binding of omeprazole and pantoprazole. These observations suggest that removal of binding of the drug to cysteine 813 accounts for the fast phase of recovery of acid secretion, and the slow recovery occurs because of delay in removal of the drug from cysteine 822 . Both residues cysteine 813 and 822 are equally labeled by pantoprazole in vivo. The small amount of cysteine 822 bound by omeprazole in vivo is not seen in vitro [51], presumably because the degree of acidification in isolated gastric vesicles is less than canalicular acidification in vivo. In vivo, it is likely that a fraction of the omeprazole remains protonated at both the pyridine and benzimidazole nitrogen and is, therefore, as for pantoprazole, slowly activated allowing access to cysteine 822 .

A similar difference was seen when the time course of labeling was determined, as shown in the lower panel of Figure 7, confirming the differential stability of binding of pantoprazole and omeprazole to the ATPase. Loss of binding was biphasic, with each phase having firstorder kinetics. The fast phase accounts for $84 \%$ of omeprazole bound, the slow phase for $16 \%$ of the drug, whereas the fast and slow phases for pantoprazole bound are approximately equal (51 and $49 \%$ respectively). These data are again explained by reversibility of almost all of the omeprazole labeling (to cysteine 813 and 892) and only partial reversibility of pantoprazole binding, namely the $51 \%$ bound to cysteine 813 .

The stoichiometry of labeling for full inhibition, namely $2.6 \mathrm{nmol} / \mathrm{mg}$ ATPase protein reflects the oligomeric nature of the active functional enzyme, since $1 \mathrm{mg}$ protein contains about 5 nmole enzyme. Hence, binding to only half of the enzyme is sufficient for full inhibition.

The above data are consistent with the slower recovery of acid secretion following pantoprazole inhibition as compared to that following omeprazole inhibition deduced from human data $[60,61]$. Whether this stability of labeling following pantoprazole labeling produces a clinical benefit, particularly in diminishing nocturnal acid breakthrough and nocturnal GERD, remains to be established.

\section{Acid suppression and other therapeutic strategies in ulcer management}

Although the incidence of peptic ulcer disease has steadily declined in the United States since the turn of the century, approximately 500,000 new cases and 4 million recurrences are reported annually. Frequent recurrence after healing has been a major component of the natural history of gastric ulcer and, without therapy, ulcers recur in 35- $80 \%$ of patients within 6-12 months of healing [62]. The major agents injurious to the upper gastrointestinal tract that are responsible for peptic ulcers are gastric acid, $H$. pylori infection, aspirin and other non-steroidal anti-inflammatory drugs (NSAIDs). Optimal patient care involves identifying and specifically treating the underlying cause. $H$. pylori is the most important risk factor for peptic ulcer disease, while aspirin and NSAIDs are the biggest culprits in peptic ulcer bleeding [63]. 


\section{H. pylori}

H. pylori can be identified in $80-90 \%$ of patients with duodenal ulcers and $50-70 \%$ of patients with gastric ulcers as compared to a $20-40 \%$ incidence in symptomatic control subjects, thus confirming its relevance in the genesis of mucosal ulceration. The prevalence of infection increases with age and socioeconomic deprivation. Numerous investigations around the world have demonstrated that most cases of chronic peptic ulcer disease are due to this infection in combination with acid secretion [64].

At this time there is little doubt that eradication of $H$. pylori is mandatory to ensure successful treatment of gastric and duodenal ulceration. Acid suppression therapy alone is associated with relatively high levels of recurrence. Thus the combination of bacterial eradication and elevation of $\mathrm{pH}$ provides the optimal treatment not only for ensuring ulcer cure, but also for abrogating the likelihood of the development of complications such as bleeding [62].

Since the bismuth triple therapy regime requires the ingestion of up to 18 tablets daily, poor compliance common and is accompanied by adverse events in about one-third of patients [64].

Since gastric acidity is an important component in the genesis of peptic ulcer disease, antisecretory therapy is of critical relevance in disease management. Thus combinations of antisecretory agents with antibiotics such as clarithromycin, tetracycline, amoxicillin and metronidazole provide high cure rates. Given the fact that PPIs are more efficacious than other classes of acid-suppressing agents in the management of peptic ulcer disease, and achieve more rapid symptom relief and ulcer healing, their combination with two of a variety of antibiotics has proved to be of considerable benefit.

Thus combinations of various PPIs such as pantoprazole, lansoprazole or omeprazole with either clarithromycin and metronidazole or clarithromycin and amoxicillin have all been reported to produce eradication rates and ulcer healing in excess of $90 \%$ and as high as $96 \%$. An issue is the duration of therapy. It seems that 7-10 days of twice daily combination therapy is required for effective eradication. Continued therapy with the PPI for 4 weeks is still suggested for gastric ulcer healing, but some studies indicate that eradication is sufficient for duodenal ulcer healing without the need for acid suppression [65].

\section{Non-steroidal antiflammatroy drugs}

The issue of whether prophylaxis by seeking and eradicating $\mathrm{H}$. pylori and by PPI use should be routinely used in the management of patients taking NSAIDs raises the question of cost-effectiveness. It seems likely that in the presence of one or more risk factors (advanced age, previous peptic ulceration and concomitant steroid administration), prophylaxis is warranted given the adverse economic and clinical impact of an NSAIDinduced complication.

\section{Other causes of ulcers}

The widespread practice of $H$. pylori eradication together with the natural decrease in $H$. pylori prevalence in Western countries has led to a relative decline in peptic ulcers attributable to $H$. pylori infection alone. Consequently, there has been a rise in the proportion of ulcers that are 'non-H. pylori, non-NSAID ulcers.' Although some may be related to surreptitious NSAID use, a gastrinoma, or gastro-duodenal Crohn's disease, many are truly 'idiopathic' and may require long-term anti-secretory agents [66]. 


\section{Acid suppression and GERD}

The prevalence of GERD has been steadily increasing on a global scale. GERD is now the most common upper gastrointestinal disorder in the Western world. In the US, and other developed counties, it is estimated that about $25 \%$ of the population currently report one or more reflux episodes weekly and GERD is rapidly becoming a problem in the developing world too. The high prevalence of reflux symptoms is mirrored by the increasing use of acid suppression medications and the rising incidence of esophageal adenocarcinoma, an important and disturbing complication of chronic GERD [67].

The introduction of two classes of gastric acid inhibitory agents, the H2RAs and PPIs, resulted in a massive amplification of the utility of medical therapy over the past three decades [68]. Two pivotal issues have required consideration in management. The first is recognition that relapse continues to be a significant event in the pharmacological management of such patients. More than $80 \%$ of the patients relapse within 6 months after cessation of therapy. Long-term drug therapy is usually necessary. The second is the recent availability of minimally invasive surgery and the suggestion that the nature and consequences of surgical intervention now require re-evaluation [67]. The enthusiasm for laparoscopically undertaken anti-reflux procedures has mounted since the initial experience reported by Dallemagne and colleagues in 1991 [69]. It is a widely held belief among surgeons that a laparoscopic procedure combines the potential of excellent long-term results with low morbidity/mortality and significant cost-effective advantages. It is unlikely that such claims can be substantiated in the long-term [70].

\section{Acid and the esophagus}

Although acid may have direct effects on the esophageal mucosa, including widening intercellular spaces and altering the esophageal potential difference, its main effect may be to facilitate the damage initiated by pepsin and bile and to activate pepsinogen to pepsin. The daily duration of time at which the intragastric $\mathrm{pH}$ is elevated to 4 or higher correlates closely with the healing of erosive reflux esophagitis. PPIs suppress acid to a greater extent than do H2RAs, thus more rapidly heal esophagitis and relieve symptoms [67]. H2RAs are not effective in anything other than the mildest GERD due to their inability to maintain a pH above 4 for a sustained period of time. Despite the efficacy of these medications, at least $10 \%$ of all patients will continue to have symptoms after PPI therapy [71].

\section{Symptom generation in GERD}

In the past, heartburn and regurgitation have been considered the typical and bestcharacterized symptoms of reflux disease. However, patients can have severe heartburn symptoms without reflux esophagitis and, conversely, GERD may cause erosions without any esophageal symptoms at all. It is increasingly appreciated that patients with GERD often have several other symptoms that contribute to low scores of psychological well-being [72].

Thus, the appreciation of the presence of diverse GERD-related symptoms as well as a substantial lack of consistency between symptomatology and the endoscopic findings in GERD have led to the realization that optimal strategies for the diagnosis and assessment of GERD require reappraisal, particularly in patients with no abnormality found at endoscopy (those with non-erosive disease, NERD), who comprise over $60 \%$ of patients with GERD [67]. Symptoms in this latter group most likely reflect esophageal motility abnormalities, or abnormal central perception of visceral signals, peripheral sensitization or esophageal hypersensitivity [73]. 
Other instruments have been developed to measure the effects of treatment in patients with GERD. The most promising thus far is a broad 'dimension-oriented' symptom evaluation tool termed ReQuest ${ }^{\mathrm{TM}}[74,75]$. This extensive patient questionnaire groups symptoms in 'clusters,' such as acid complaints, upper abdominal/stomach complaints, lower abdominal/ digestive complaints, nausea, sleep disturbances and others, and also contains a general well-being dimension. Using this as a tool, it was found that complete remission of GERD required both analysis of symptom relief and endoscopic evaluation of esophageal healing [76].

\section{Intravenous PPI therapy of gastrointestinal bleeding}

\section{Management of upper gastrointestinal hemorrhage}

Upper gastrointestinal hemorrhage and stress ulceration in critically ill patients are common events associated with substantial morbidity and costs to the health care system. Bleeding ceases spontaneously in up to $80 \%$ of cases but, despite the development of new pharmacological and endoscopic interventions, the mortality of upper gastrointestinal hemorrhage is high, ranging from about $10 \%$ in patients who present to a hospital with acute bleeding to over $30 \%$ in those whose bleeding develops while they are in hospital. Furthermore, there has been little reduction in the overall mortality over the last four decades, although there is some evidence that mortality rates may be less if patients are managed in a specialist gastrointestinal bleeding unit.

The management of upper gastrointestinal bleeding encompasses initial resuscitation measures, pharmacological therapy, endoscopic therapy and surgery [77]. Pharmacological therapy includes the administration of acid suppressants (H2RAs or PPIs), splanchnic blood flow modulators (somatostatin, octreotide) or anti-fibrinolytics (tranexamic acid, epsilon aminocaproic acid). Prompt endoscopy can treat bleeding lesions and establish the likely rebleeding risk through the identification of endoscopic stigmata.

Severely ill patients in intensive care units - particularly those on mechanical ventilators and with coagulopathy - are prone to upper gastrointestinal bleeding from 'stress' ulceration caused by chronic gastric mucosal ischemia [78].

\section{The evidence for individual management strategies}

\section{Gastroduodenal bleeding}

Intravenous H2RAs are of no benefit for bleeding duodenal ulcers and only modestly effective in bleeding gastric ulcers [79]. Because PPIs have a greater inhibitory effect on gastric acid secretion than $\mathrm{H} 2 \mathrm{RAs}$, a recent meta-analysis concluded that PPIs produced a $50 \%$ reduction in rebleeding, a 53\% reduction in need for surgery and a non-significant $8 \%$ decrease in deaths [80], demonstrating the superiority of PPIs to H2RAs, although they do not appear to reduce mortality.

\section{Stress ulceration}

Prophylactic administration of antacids or H2RAs decreases the incidence of overt bleeding in stress ulceration (though not mortality), with H2RAs more effective than antacids [81]. If the benefits of H2RAs are due to reduction in gastric acidity, PPIs would be expected to produce a greater decrease in stress ulcer-related complications, because PPIs are, ab initio, more effective than $\mathrm{H} 2 \mathrm{RAs}$ at increasing gastric $\mathrm{pH}$ and, in part, because tolerance to intravenous H2RAs develops within $72 \mathrm{~h}$ of starting therapy. However, there are currently no convincing data to support the prophylactic use of PPIs, orally or intravenously, to prevent the development of stress ulceration in critically ill patients. 
Intravenous acid inhibitory therapy-Oral therapy is limited in terms of its efficacy and may not be feasible in critically ill patients, for example, in patients at very high risk of stress ulcers in intensive care units and the bleeding ulcer patient where acidity of gastric contents would not only exacerbate the cause of bleeding but would also enable dissolution of the thrombus. A list of conditions for which intravenous acid inhibition should be considered is listed in Table 2.

\section{Histamine $\mathrm{H} 2$ receptor antagonists}

These are water-soluble, neutral-pH, stable compounds that can readily be formulated as solutions ready to inject. Given their stability, they can either be given as bolus or continuous infusion. Little difference exists between individual H2RAs in terms of acid control with intravenous administration. Continuous infusion gives the best control of acid secretion. Unfortunately, relatively few controlled clinical trials have been performed on the effectiveness of many of intravenous H2RAs and their major drawback is the inevitable tolerance that ensues after short-term therapy. The mechanism of this approximately $50 \%$ loss of efficacy is most likely due to upregulation of muscarinic pathways of stimulation of acid secretion.

\section{Proton pump inhibitors}

The advent of PPIs opened up the possibility of more reliable $\mathrm{pH}$ control by the intravenous route. Since the target of these drugs, the H,K ATPase, is the final step of acid secretion, there is no bypass of inhibition and no tolerance of the effect. However, it is thought that PPIs require stimulation of acid secretion for efficacy. After oral administration, the half-life of PPIs is about $90 \mathrm{~min}$, thus oral administration is given with or just before meals. Further, since these compounds require an active acid pump and not all acid pumps are active upon administration, the rate of inhibition of acid secretion by intravenous administration may be somewhat delayed compared to H2RAs. Certainly, with oral dosing, because of the separation between the time at which active pumps are present in the stomach and the dwell time of the PPI in the blood, there is improvement in inhibition of acid secretion with the days of single-dose administration, steady-state inhibition being achieved after 3-5 days of therapy [82].

The chemistry of the compounds makes it impossible in their current structure to formulate an intravenous solution that has a sufficient shelf-life, since even a solution of $\mathrm{pH} 9$ has sufficient protons to eventually activate the drug. The active drug is able to react with any SH group and is positively charged, therefore it is inactivated in the stomach or in the blood without being able to target the acid pump. Because intravenous omeprazole is not available in the USA and in many other countries, other means of administering the compound in solution form have been devised. A comparison of intravenous H2RAs with PPIs was first performed in dogs, using continuous pentagas-trin infusion to mimic the effect of food stimulation and to optimize the effect of intravenous PPI injection. The PPI showed clear superiority in terms of duration of effect since the release of histamine from the ECL cell by pentagastrin infusion eventually bypassed the effect of famotidine since this had disappeared from the blood [83]. However, in humans, acid secretion is a continuous process so that over an 8-h period, all pumps go through a cycle of stimulation. For intravenous therapy, with the higher dose that can be given, it is possible that steady-state effects can be seen on acid secretion in the fasted patient, as would be encountered in intensive care unit settings and pre-operatively, thus extending the benefit of pump inhibition to the usual intravenous setting. Administration of single intravenous doses of omeprazole at $80 \mathrm{mg}$ resulted in $80 \%$ inhibition of peak acid output at 90 min after dose and $60 \% 24 \mathrm{~h}$ after dose that was about the same as that achieved by repetitive dosing for 6 days [84]. A study on Zollinger-Ellison patients showed also that $60 \mathrm{mg}$ omeprazole administered by injection every $12 \mathrm{~h}$ reduced 
acid secretion to $5 \mathrm{mEq} / \mathrm{h}$, providing at least equal efficacy to continuous intravenous infusion of ranitidine. After thermocoagula-tion to stop bleeding, an 80-mg bolus dose of omeprazole followed by an $8 \mathrm{mg} / \mathrm{h}$ infusion (previously shown to elevate intragastric $\mathrm{pH}$ to 6.0) for 3 days followed by $20 \mathrm{mg}$ daily for 8 weeks resulted in $7 \%$ recurrence of bleeding within 30 days in the omeprazole group compared to $23 \%$ in the placebo group, with most recurrences occurring in the first 3 days of treatment [85].

Pantoprazole is also available in an intravenous formulation. It is inherently more acid stable than omeprazole, esomeprazole or lansoprazole, and hence does not require as alkaline a buffer for reconstitution. Intravenous pantoprazole resulted in as rapid an elevation to $\mathrm{pH}$ $\geq 4.0$ as cimetidine and when given three times daily proved superior to continuous cimetidine in $\mathrm{pH}$ control by the second day. Eight miligrams was superior to $40 \mathrm{mg}$, indicating that $80 \mathrm{mg}$ is the minimum dose to be recommended, with 8-hourly dosing giving better results and without the problems of tolerance exhibited by H2RAs. Furthermore, this showed the efficacy of PPIs in fasting patients [86].

In general, therefore, intravenous PPIs are preferred to infusion of H2RAs. Bolus injection of H2RAs is no longer indicated. A formulation or modification of PPI structure to allow continuous intravenous infusion of a neutral $\mathrm{pH}$ solution so as to bring gastric volume down to close to zero and to elevate $\mathrm{pH}$ to 6.0 is also desirable.

\section{Future directions for acid inhibitory drugs Improvements in PPIs}

There is little that can be done to alter the mechanism of activation of PPIs or the requirement that gastric acidification is present for their activity. What may be amenable to future research is to generate PPIs with a much longer residence time in the blood so that more pumps are inhibited or so that bedtime dosing can be achieved. One such approach is to generate a compound with slower metabolism. The pyrrole-substituted PPI, ilaprazole, may be such a compound, and the imidazopryidine, tenatoprazole, is clearly a candidate compound with an 8-h half-life [87]. Another approach is to generate a structure such as a sulfonamide derivative of any of the PPIs, thereby delaying absorption that results in a longer plasma dwell time [88].

\section{$\mathrm{K}^{+}$competitive antagonists}

The synthesis of the imidazo[1,2 $\alpha$ ]pyridine, $\mathrm{SCH} 28080$ [21], resulted in the generation of a high-affinity reversible inhibitor of the $\mathrm{H}, \mathrm{K}$ ATPase that bound selectively to the $\mathrm{E}_{2} \mathrm{P}$ or $\mathrm{E}_{2}$ form of the enzyme $[22,23]$. This results in an acid-independent mechanism of inhibition where only a half cycle is required for inhibition to occur with the formation of the $\mathrm{E}_{2} \mathrm{P}$ conformer [32]. Then, acid secretion would be more rapidly inhibited and more effectively, but in contrast to the PPIs, inhibition would be dependent entirely on the plasma concentration of the compound, as is the case for most targeted drugs. The difficulty that has plagued this approach is the generation, not only of a high-affinity H,K ATPase inhibitor, but also the syntheses of a drug that has an adequate margin of safety. Since these compounds are reversible, their site of binding cannot be determined simply by identification of the fragment of the ATPase that is labeled, but must rely on the effects of site-directed mutations on the affinity and on the retention of the $\mathrm{K}^{+}$competitive nature of the compound.

A key observation was that inhibition by omeprazole and $\mathrm{SCH} 2808$ was mutually exclusive, indicating an overlap in the binding region of these two compounds, and this allowed orientation of the SCH28080 in the same general domain as omeprazole. Site-directed mutations then enabled a more exact docking structure for the $\mathrm{K}^{+}$competitive antagonists, 
which could then be confirmed by varying the structure of the inhibitor and correlating the $\mathrm{K}_{\mathrm{i}}$ of such compounds with the docking site model.

Mutations toward the exoplasmic surface of TM4, TM5, TM6, the loop between TM5 and TM6 and one site at the end of TM8 altered either the $\mathrm{K}_{\mathrm{i}}$ or changed the nature of inhibition from strictly competitive to mixed or even non-competitive without affecting ion affinity. The latter observations indicate that these mutations allow simultaneous occupancy of the inhibitor-binding site and the ion-binding domain, which does not happen in the wild-type enzyme. These observations are interpreted as showing that the particular mutations generate a space whereby $\mathrm{K}^{+}$can bypass the inhibitor allowing access to the ion domain situated above the inhibitor-binding region. Mutation of lysine 791 to serine greatly reduced enzyme activity as well as increasing the $\mathrm{K}_{\mathrm{i}}$ for $\mathrm{SCH} 28080$ as expected from its key role in proton secretion by the pump $[50,89]$.

Using the various mutational data, it was possible to generate a model showing the docking of an imidazo-naphthyridine (Byk36399) to the membrane domain of the H,K ATPase. This fused ring structure was generated to mimic the calculated structure of the imidazopyridines shown in the left side of Figure 8 . When the $\mathrm{R}$ in the bottom structure was hydrogen, the $\mathrm{K}_{\mathrm{i}}$ of this compound was found to be $47 \mathrm{nM}$ similar to the $56 \mathrm{nM}$ determined for SCH28080. However, when a methyl group was used to replace the hydrogen, the $\mathrm{K}_{\mathrm{i}}$ rose to $\sim 1 \mathrm{mM}$. This finding is explained in the model on the right side of Figure 8 where there is interference with binding due to the presence of the methyl group on the nitrogen of the tricyclic structure. This modeling approach may help define different $\mathrm{K}^{+}$competitive antagonists with a different fundamental core structure such as a benzimidazole. An improvement in the safety, plasma half-life and affinity of the APA class of drug may eventually lead to their replacing PPIs as the therapeutic choice in treatment of acid-related diseases. Two clear advantages are rapidity of onset of action for on-demand therapy, and aqueous-solution stability more suitable for intravenous administration. Their lack of acid sensitivity also makes them more suitable for administration to patients via a nasogastric tube.

\section{Conclusions}

The development of safe and potent inhibitors of acid secretion built upon the elucidation of the normal regulation of acid secretion by physiologists and pharmacologists of the early part of the 20th century. The initial success of H2RAs was subsequently surpassed by the rational development of the even more effective PPIs, a major medical success story for the treatment of peptic ulcer disease and GERD. Together with the recognition of H. pylori, this has resulted in a decline of the incidence of chronic peptic ulcer disease, once one of the most common chronic medical conditions, and virtually abolished the need for peptic ulcer disease surgery with its attendant complications. The increase in GERD worldwide over the last 30 years is one of the major indications for continued PPI use and has led to this class of drugs being the most commonly prescribed compounds in the world. While potent acid suppression has helped alleviate much suffering from erosive GERD, there has been recent recognition that patients with GERD suffer from a broad complex of symptoms in addition to the cardinal symptom complex of heartburn and regurgitation, and realization that GERD without endoscopic evidence of damage (NERD) is an important and increasing medical problem.

Improved understanding of the molecular and cellular events responsible for gastric acid secretion has in recent years led to the development of further novel agents, including reversible antagonists of the parietal cell proton pumps, that may be capable of providing 
faster and longer-lasting acid suppression than the PPIs. Their clinical role in GERD and other acid-related diseases will be defined in the next few years.

\section{References}

1. Black JW, Duncan WAM, Durant CJ, Ganellin CR, Parsons ME. Definition and antagonism of histamine H2 receptors. Nature. 1972; 236:385-390. [PubMed: 4401751]

2. Hirschowitz BI, Sachs G. Atropine inhibition of insulin-, histamine-, and pentagastrin-stimulated gastric electrolyte and pepsin secretion in the dog. Gastroenterology. 1969; 56:693-702. [PubMed: 4390359]

3. Sachs G, Chang HH, Rabon E, Schackman R, Lewin M, Saccomani G. A nonelectrogenic H+ pump in plasma membranes of hog stomach. J Biol Chem. 1976; 251:7690-7698. [PubMed: 12175]

4. Chang H, Saccomani G, Rabon E, Schackmann R, Sachs G. Proton transport by gastric membrane vesicles. Biochim Biophys Acta. 1977; 464:313-327. [PubMed: 12816]

5. Forte JG, Ganser A, Beesley R, Forte TM. Unique enzymes of purified microsomes from pig fundic mucosa: K+-stimulated adenosine triphosphatase and K+-stimulated pNPPase. Gastroenterology. 1975; 69:175-189. [PubMed: 238896]

6. Ganser AL, Forte JG. K +-stimulated ATPase in purified microsomes of bullfrog oxyntic cells. Biochim Biophys Acta. 1973; 307:169-180. [PubMed: 4351147]

7. Saccomani G, Shah G, Spenney JG, Sachs G. Characterization of gastric mucosal membranes. VIII. The localization of peptides by iodination and phosphorylation. J Biol Chem. 1975; 250:4802-4809. [PubMed: 167006]

8. Modlin IM. From Prout to the proton pump - a history of the science of gastric acid secretion and the surgery of peptic ulcer. Surg Gynecol Obstet. 1990; 170:81-96. [PubMed: 2152987]

9. Wilkes JM, Kajimura M, Scott DR, Hersey SJ, Sachs G. Muscarinic responses of gastric parietal cells. J Membr Biol. 1991; 122:97-110. [PubMed: 1895339]

10. Carmine AA, Brogden RN. Pirenzepine: a review of its pharmacodynamic and pharmacokinetic properties and therapeutic efficacy in peptic ulcer disease and other allied diseases. Drugs. 1985; 30:85-126. [PubMed: 3928324]

11. McCarthy DM, Olinger EJ, May RJ, Long BW, Gardner JD. H2-Histamine receptor blocking agents in the Zollinger-Ellison syndrome: experience in seven cases and implications for long-term therapy. Ann Intern Med. 1977; 87:668-675. [PubMed: 22304]

12. Wilder-Smith $\mathrm{CH}$, Merki HS. Tolerance during dosing with $\mathrm{H} 2$-receptor antagonists: an overview. Scand J Gastroenterol Suppl. 1992; 193:14-19. [PubMed: 1363254]

13. Modlin IM, Sachs G, Wright N, Kidd M. Edkins and a century of acid suppression. Digestion. 2005; 72:129-145. [PubMed: 16172550]

14. Calam J, Gibbons A, Healey ZV, Bliss P, Arebi N. How does Helicobacter pylori cause mucosal damage? Its effect on acid and gastrin physiology. Gastroenterology. 1997; 113 (6 Suppl):S43-9. [PubMed: 9394759]

15. Leban JJ, Kull FC Jr, Landavazo A, Stockstill B, McDermed JD. Development of potent gastrinreleasing peptide antagonists having a D-Pro-psi(CH2NH)-Phe-NH2 C terminus. Proc Natl Acad Sci USA. 1993; 90:1922-1926. [PubMed: 8446610]

16. Buck IM, Black JW, Cooke T, Dunstone DJ, Gaffen JD, Griffin EP, Harper EA, Hull RA, Kalindjian SB, Lilley EJ, Linney ID, Low CM, McDonald IM, Pether MJ, Roberts SP, Shankley NP, Shaxted ME, Steel KI, Sykes DA, Tozer MJ, Watt GF, Walker MK, Wright L, Wright PT. Optimization of the in vitro and in vivo properties of a novel series of 2,4,5-trisubstituted imidazoles as potent cholecystokinin-2 (CCK2) antagonists. J Med Chem. 2005; 48:6803-6812. [PubMed: 16250639]

17. Prinz C, Zanner R, Gratzl M. Physiology of gastric enterochromaffin-like cells. Annu Rev Physiol. 2003; 65:371-382. [PubMed: 12221195]

18. Fellenius E, Berglindh T, Sachs G, Olbe L, Elander B, Sjostrand SE, Wallmark B. Substituted benzimidazoles inhibit gastric acid secretion by blocking $(\mathrm{H}++\mathrm{K}+)$ ATPase. Nature. 1981; 290:159-161. [PubMed: 6259537] 
19. Wallmark B, Sachs G, Mardh S, Fellenius E. Inhibition of gastric $(\mathrm{H}++\mathrm{K}+)$-ATPase by the substituted benzimidazole, picoprazole. Biochim Biophys Acta. 1983; 728:31-38. [PubMed: 6299338]

20. Shin JM, Sachs G. Restoration of acid secretion following treatment with proton pump inhibitors. Gastroenterology. 2002; 123:1588-1597. [PubMed: 12404233]

21. Kaminski JJ, Bristol JA, Puchalski C, Lovey RG, Elliott AJ, Guzik H, Solomon DM, Conn DJ, Domalski MS, Wong SC, Gold EJ, Long JF, Chiu PJS, Steinberg M, McPhail AT. Antiulcer agents. 1 Gastric antisecretory and cytoprotective properties of substituted imidazo[1,2a]pyridines. J Med Chem. 1985; 28:876-892. [PubMed: 4009611]

22. Wallmark B, Briving C, Fryklund J, Munson K, Jackson R, Mendlein J, Rabon E, Sachs G. Inhibition of gastric $\mathrm{H}+, \mathrm{K}+-\mathrm{ATPase}$ and acid secretion by $\mathrm{SCH} 28080$, a substituted pyridyl(1,2a)imidazole. J Biol Chem. 1987; 262:2077-2084. [PubMed: 3029064]

23. Shull GE, Lingrel JB. Molecular cloning of the rat stomach $(\mathrm{H}++\mathrm{K}+)$-ATPase. J Biol Chem. 1986; 261:16788-16791. [PubMed: 3023364]

24. Maeda M, Ishizaki J, Futai M. cDNA cloning and sequence determination of pig gastric $(\mathrm{H}++\mathrm{K}$ +)-ATPase. Biochem Biophys Res Commun. 1988; 157:203-209. [PubMed: 2848518]

25. Bamberg K, Mercier F, Reuben MA, Kobayashi Y, Munson KB, Sachs G. cDNA cloning and membrane topology of the rabbit gastric $\mathrm{H}+/ \mathrm{K}(+)$-ATPase alpha-subunit. Biochim Biophys Acta. 1992; 1131:69-77. [PubMed: 1316171]

26. Maeda M, Oshiman K, Tamura S, Futai M. Human gastric $(\mathrm{H}++\mathrm{K}+)-A T P a s e$ gene. Similarity to $(\mathrm{Na}++\mathrm{K}+)$-ATPase genes in exon/intron organization but difference in control region. J Biol Chem. 1990; 265:9027-9032. [PubMed: 2160952]

27. Munson K, Garcia R, Sachs G. Inhibitor and ion binding sites on the gastric H,K-ATPase. Biochemistry. 2005; 44:5267-5284. [PubMed: 15807521]

28. Rabon EC, McFall TL, Sachs G. The gastric [H,K]ATPase:H+/ATP stoichiometry. J Biol Chem. 1982; 257:6296-6299. [PubMed: 6281267]

29. Sweadner KJ, Donnet C. Structural similarities of Na,K-ATPase and SERCA, the Ca(2+)-ATPase of the sarcoplasmic reticulum. Biochem J. 2001; 356:685-704. [PubMed: 11389677]

30. Post RL. Seeds of sodium, potassium ATPase. Annu Rev Physiol. 1989; 51:1-15. [PubMed: 2540695]

31. Abe K, Kaya S, Hayashi Y, Imagawa T, Kikumoto M, Oiwa K, Katoh T, Yazawa M, Taniguchi K. Correlation between the activities and the oligomeric forms of pig gastric H/K-ATPase. Biochemistry. 2003; 42:15132-15138. [PubMed: 14690423]

32. Shin JM, Grundler G, Senn-Bilfinger J, Simon WA, Sachs G. Functional Consequences of the Oligomeric Form of the Membrane-Bound Gastric H,K-ATPase. Biochemistry. 2005; 44:1632116332. [PubMed: 16331993]

33. Taniguchi K, Kaya S, Abe K, Mardh S. The oligomeric nature of Na/K-transport ATPase. J Biochem (Tokyo). 2001; 129:335-342. [PubMed: 11226871]

34. Bamberg K, Sachs G. Topological analysis of $\mathrm{H}+, \mathrm{K}(+)$-ATPase using in vitro translation. J Biol Chem. 1994; 269:16909-16919. [PubMed: 8207013]

35. Vagin O, Denevich S, Munson K, Sachs G. SCH28080, a K+-competitive inhibitor of the gastric $\mathrm{H}, \mathrm{K}-\mathrm{ATPase}$, binds near the M5-6 luminal loop, preventing $\mathrm{K}+$ access to the ion binding domain. Biochemistry. 2002; 41:12755-12762. [PubMed: 12379118]

36. Jorgensen PL, Hakansson KO, Karlish SJ. Structure and mechanism of Na,K-ATPase: functional sites and their interactions. Annu Rev Physiol. 2003; 65:817-849. [PubMed: 12524462]

37. Blostein R, Dunbar L, Mense M, Scanzano R, Wilczynska A, Caplan MJ. Cation selectivity of gastric H,K-ATPase and Na,K-ATPase chimeras. J Biol Chem. 1999; 274:18374-18381. [PubMed: 10373442]

38. McIntosh DB, Clausen JD, Woolley DG, MacLennan DH, Vilsen B, Andersen JP. Roles of conserved $\mathrm{P}$ domain residues and $\mathrm{Mg} 2+\mathrm{in} \mathrm{ATP}$ binding in the ground and $\mathrm{Ca} 2+$-activated states of sarcoplasmic reticulum Ca2+-AT-Pase. J Biol Chem. 2004; 279:32515-32523. [PubMed: 15133025]

39. De Pont JJ, Swarts HG, Willems PH, Koenderink JB. The E1/E2-preference of gastric H,KATPase mutants. Ann NY Acad Sci. 2003; 986:175-182. [PubMed: 12763793] 
40. Reuben MA, Lasater LS, Sachs G. Characterization of a beta subunit of the gastric $\mathrm{H}+/ \mathrm{K}(+)-$ transporting ATPase. Proc Natl Acad Sci USA. 1990; 87:6767-6771. [PubMed: 2168558]

41. Shull GE. cDNA cloning of the beta-subunit of the rat gastric H,K-ATPase. J Biol Chem. 1990; 265:12123-12126. [PubMed: 2165052]

42. Toh BH, Gleeson PA, Simpson RJ, Moritz RL, Callaghan JM, Goldkorn I, Jones CM, Martinelli TM, Mu FT, Humphris DC, Pettit JM, Mori Y, Masuda T, Sobeiszczuk P, Weinstock J, Mantamadiotis T, Baldwin G. The 60- to 90-kDa parietal cell autoantigen associated with autoimmune gastritis is a beta subunit of the gastric $\mathrm{H}+/ \mathrm{K}(+)$-ATPase (proton pump). Proc Natl Acad Sci USA. 1990; 87:6418-6422. [PubMed: 1974721]

43. Blanco G, Mercer RW. Isozymes of the Na-K-ATPase: heterogeneity in structure, diversity in function. Am J Physiol. 1998; 275:F633-650. [PubMed: 9815123]

44. Toyoshima C, Asahi M, Sugita Y, Khanna R, Tsuda T, MacLennan DH. Modeling of the inhibitory interaction of phospholamban with the Ca2+ ATPase. Proc Natl Acad Sci USA. 2003; 100:467-472. [PubMed: 12525698]

45. Toyoshima C, Nakasako M, Nomura H, Ogawa H. Crystal structure of the calcium pump of sarcoplasmic reticulum at 2.6 A resolution. Nature. 2000; 405:647-655. [PubMed: 10864315]

46. Toyoshima C, Nomura H, Sugita Y. Crystal structures of Ca2+-ATPase in various physiological states. Ann NY Acad Sci. 2003; 986:1-8. [PubMed: 12763767]

47. Melle-Milovanovic D, Milovanovic M, Nagpal S, Sachs G, Shin JM. Regions of association between the alpha and the beta subunit of the gastric H,K-ATPase. J Biol Chem. 1998; 273:11075-11081. [PubMed: 9556592]

48. Shin JM, Sachs G. Identification of a region of the H,K-ATPase alpha subunit associated with the beta subunit. J Biol Chem. 1994; 269:8642-8646. [PubMed: 8132592]

49. Hebert H, Purhonen P, Vorum H, Thomsen K, Maunsbach AB. Three-dimensional structure of renal Na,K-ATPase from cryo-electron microscopy of two-dimensional crystals. J Mol Biol. 2001; 314:479-494. [PubMed: 11846561]

50. Munson K, Vagin O, Sachs G, Karlish S. Molecular modeling of SCH28080 binding to the gastric H,K-ATPase and MgATP interactions with SERCA- and Na,K-ATPases. Ann NY Acad Sci. 2003; 986:106-110. [PubMed: 12763782]

51. Shin JM, Cho YM, Sachs G. Chemistry of covalent inhibition of the gastric $(\mathrm{H}+, \mathrm{K}+)$-ATPase by proton pump inhibitors. J Am Chem Soc. 2004; 126:7800-7811. [PubMed: 15212527]

52. Shin JM, Homerin H, Domagala F, Ficheux H, Sachs G. Characterization of the inhibitory activity of tenatoprazole on the gastric H+,K+-ATPase in vitro and in vivo. Biochem Pharmacol. 2006; 71:837-849. [PubMed: 16405921]

53. Besancon M, Shin JM, Mercier F, Munson K, Miller M, Hersey S, Sachs G. Membrane topology and omeprazole labeling of the gastric $\mathrm{H}+, \mathrm{K}(+)$ - adenosinetriphosphatase. Biochemistry. 1993; 32:2345-2355. [PubMed: 8382947]

54. Sachs G, Shin JM, Besancon M, Prinz C. The continuing development of gastric acid pump inhibitors. Aliment Pharmacol Ther. 1993; 7:4-12. [PubMed: 8387826]

55. Shin JM, Besancon M, Simon A, Sachs G. The site of action of pantoprazole in the gastric $\mathrm{H}+$ / K(+)-ATPase. Biochim Biophys Acta. 1993; 1148:223-233. [PubMed: 8389196]

56. Shin JM, Sachs G. Differences in binding properties of two proton pump inhibitors on the gastric $\mathrm{H}$ ,+ K+-ATPase in vivo. Biochem Pharmacol. 2004; 68:2117-2127. [PubMed: 15498502]

57. Gedda K, Scott D, Besancon M, Lorentzon P, Sachs G. Turnover of the gastric $\mathrm{H}+, \mathrm{K}(+)$-adenosine triphosphatase alpha subunit and its effect on inhibition of rat gastric acid secretion. Gastroenterology. 1995; 109:1134-1141. [PubMed: 7557078]

58. Im WB, Blakeman DP, Davis JP. Irreversible inactivation of rat gastric (H+-K+)-ATPase in vivo by omeprazole. Biochem Biophys Res Commun. 1985; 126:78-82. [PubMed: 2982382]

59. Wallmark B, Larsson H, Humble L. The relationship between gastric acid secretion and gastric $\mathrm{H}$ +,K+-ATPase activity. J Biol Chem. 1985; 260:13681-13684. [PubMed: 2997178]

60. Dammann HG, Burkhardt F. Pantoprazole versus omeprazole: influence on meal-stimulated gastric acid secretion. Eur J Gastroenterol Hepatol. 1999; 11:1277-1282. [PubMed: 10563540] 
61. Katashima M, Yamamoto K, Tokuma Y, Hata T, Sawada Y, Iga T. Comparative pharmacokinetic/ pharmacodynamic analysis of proton pump inhibitors omeprazole, lansoprazole and pantoprazole, in humans. Eur J Drug Metab Pharmacokinet. 1998; 23:19-26. [PubMed: 9625268]

62. Yuan Y, Padol IT, Hunt RH. Peptic ulcer disease today. Nat Clin Pract Gastroenterol. 2006; 3:8089.

63. Huang JQ, Sridhar S, Hunt RH. Role of Helicobacter pylori infection and non-steroidal antiinflammatory drugs in peptic-ulcer disease: a meta-analysis. Lancet. 2002; 359:14-22. [PubMed: 11809181]

64. Suerbaum S, Michetti P. Helicobacter pylori infection. N Engl J Med. 2002; 347:1175-1186. [PubMed: 12374879]

65. Delaney B, Moayyedi P, Forman D. Helicobacter pylori infection. Clin Evid. 2006; 15:1-2. [PubMed: 16973003]

66. Hung LC, Ching JY, Sung JJ, To KF, Hui AJ, Wong VW, Leong RW, Chan HL, Wu JC, Leung WK, Lee YT, Chung SC, Chan FK. Long-term outcome of Helicobacter pylori-negative idiopathic bleeding ulcers: a prospective cohort study. Gastroenterology. 2005; 128:1845-1850. [PubMed: 15940620]

67. Moayyedi P, Talley NJ. Gastro-oesophageal reflux disease. Lancet. 2006; 367:2086-2100. [PubMed: 16798392]

68. Shaheen NJ, Hansen RA, Morgan DR, Gangarosa LM, Ringel Y, Thiny MT, Russo MW, Sandler RS. The burden of gastrointestinal and liver diseases, 2006. Am J Gastroenterol. 2006; 101:21282138. [PubMed: 16848807]

69. Dallemagne B, Weerts JM, Jehaes C, Markiewicz S, Lombard R. Laparoscopic Nissen fundoplication: preliminary report. Surg Laparosc Endosc. 1991; 1:138-143. [PubMed: 1669393]

70. Vakil N, Shaw M, Kirby R. Clinical effectiveness of laparoscopic fundoplication in a U.S. community. Am J Med. 2003; 114:1-5. [PubMed: 12543281]

71. Vaezi MF. 'Refractory GERD': acid, nonacid, or not GERD? Am J Gastroenterol. 2004; 99:989_ 991. [PubMed: 15180714]

72. Vakil N, van Zanten SV, Kahrilas P, Dent J, Jones R. Global Consensus Group. The Montreal definition and classification of gastroesophageal reflux disease: a global evidence-based consensus. Am J Gastroenterol. 2006; 101:1900-1920. [PubMed: 16928254]

73. Quigley EM. Functional dyspepsia (FD) and non-erosive reflux disease (NERD): overlapping or discrete entities? Best Pract Res Clin Gastroenterol. 2004; 18:695-706. [PubMed: 15324708]

74. Stanghellini V, Armstrong D, Monnikes H, Bardhan KD. Systematic review: do we need a new gastro-oesophageal reflux disease questionnaire? Aliment Pharmacol Ther. 2004; 19:463-479. [PubMed: 14987316]

75. Armstrong D, Monnikes H, Bardhan KD, Stanghellini V. The construction of a new evaluative GERD questionnaire - methods and state of the art. Digestion. 2004; 70:71-78. [PubMed: 15334021]

76. Bardhan KD, Achim A, Riddermann T, Pfaffenberger B. A clinical trial comparing pantoprazole and esomeprazole to explore the concept of achieving 'complete remission' in gastro-oesophageal reflux disease. Aliment Pharmacol Ther. 2007; 25:1461-1469. [PubMed: 17539986]

77. Barkun A, Bardou M, Marshall JK. Consensus recommendations for managing patients with nonvariceal upper gastrointestinal bleeding. Ann Intern Med. 2003; 139:843-857. [PubMed: 14623622]

78. Cash BD. Evidence-based medicine as it applies to acid suppression in the hospitalized patient. Crit Care Med. 2002; 30(6 suppl):S373-378. [PubMed: 12072665]

79. Levine JE, Leontiadis GI, Sharma VK, Howden CW. Meta-analysis: the efficacy of intravenous H2-receptor antagonists in bleeding peptic ulcer. Aliment Pharmacol Ther. 2002; 16:1137-1142. [PubMed: 12030956]

80. Zed PJ, Loewen PS, Slavik RS, Marra CA. Meta-analysis of proton pump inhibitors in treatment of bleeding peptic ulcers. Ann Pharmacother. 2001; 35:1528-1534. [PubMed: 11793613]

81. Cook DJ, Reeve BK, Guyatt GH, Heyland DK, Griffith LE, Buckingham L, Tryba M. Stress ulcer prophylaxis in critically ill patients. Resolving discordant meta-analyses. JAMA. 1996; 275:308314. [PubMed: 8544272] 
82. Kromer W, Postius S, Riedel R. Animal pharmacology of reversible antagonism of the gastric acid pump, compared to standard antisecretory principles. Pharmacology. 2000; 60:179-187. [PubMed: 10828742]

83. Larsson H, Carlsson E, Junggren U, Olbe L, Sjostrand SE, Skanberg I, Sundell G. Inhibition of gastric acid secretion by omeprazole in the dog and rat. Gastroenterology. 1983; 85:900-917. [PubMed: 6884713]

84. Huggins RM, Scates AC, Latour JK. Intravenous proton-pump inhibitors versus H2-antagonists for treatment of GI bleeding. Ann Pharmacother. 2003; 37:433-437. [PubMed: 12639176]

85. Lanas A, Artal A, Blas JM, Arroyo MT, Lopez-Zaborras J, Sainz R. Effect of parenteral omeprazole and ranitidine on gastric $\mathrm{pH}$ and the outcome of bleeding peptic ulcer. J Clin Gastroenterol. 1995; 21:103-106. [PubMed: 8583073]

86. Smith J, Karlstadt R. Rapid gastric pH improvement from NPO to enteral-fed period with intermittent intravenous (IV) pantoprazole (P) vs. continually infused cimetidine (C). Am J Gastroenterol. 2003; 98:S41.

87. Hunt RH, Armstrong D, James C, Chowdhury SK, Yuan Y, Fiorentini P, Taccoen A, Cohen P. Effect on intragastric $\mathrm{pH}$ of a PPI with a prolonged plasma half-life: comparison between tenatoprazole and esomeprazole on the duration of acid suppression in healthy male volunteers. Am J Gastroenterol. 2005; 100:1949-1956. [PubMed: 16128938]

88. Hunt RH, Armstrong D, Yaghoobi M, James C, Chen Y, Leonard J, Shin JM, Sachs G. AGN 201904-Z (AGN), a novel enteric-coated PPI, produces greater, more prolonged acid suprression than esomeprazole (ESO) in male healthy volunteers. Am J Gastroenterol. 2006; 101 (suppl):S 92.

89. Munson K, Law RJ, Sachs G. Analysis of the gastric H,K ATPase for ion pathways and inhibitor binding sites. Biochemistry. 2007; 46:5398-5417. [PubMed: 17425287] 


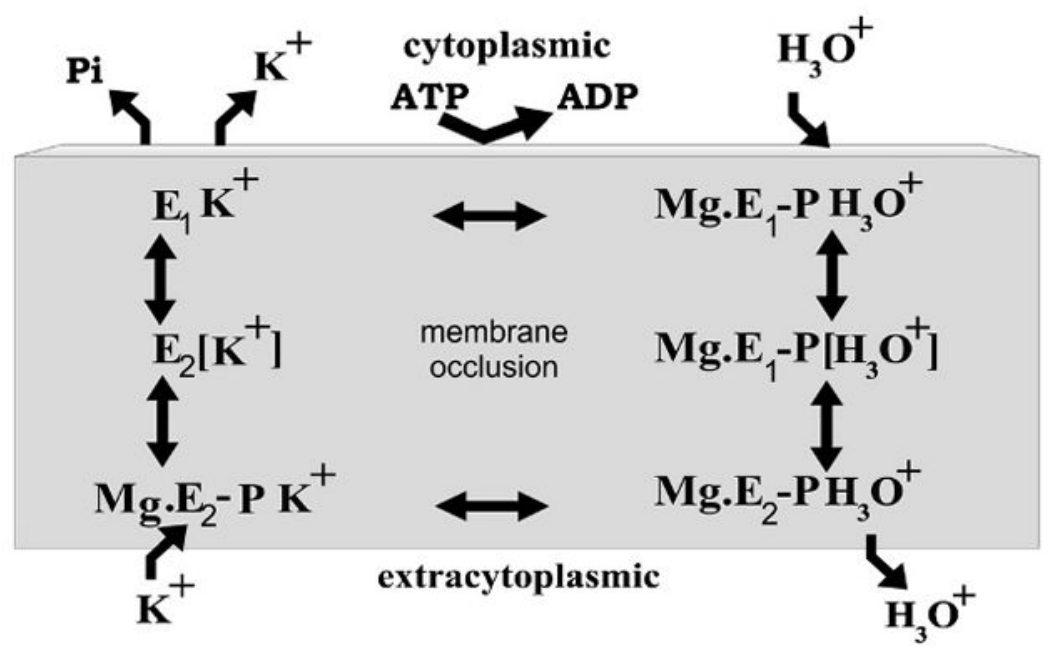

Figure 1.

The catalytic cycle of the gastric H,K ATPase at high acidity in the parietal cell secretory canaliculus. With the binding of a hydronium ion from the cytoplasmic surface of the enzyme, MgATP phosphorylates an aspartic acid residue (Asp386) to form the first ion transport intermediate in the $\mathrm{E}_{1} \mathrm{P}$ form which then converts by a conformational change to the second ion transport form, $\mathrm{E}_{2} \mathrm{P}$, with the ion site now exposed to the exterior, and hydronium is released at $\mathrm{pH} \sim 1.0 . \mathrm{K}^{+}$from the outside surface binds to this form, to the same region from which the hydronium was released, and the enzyme dephosphorylates, thus trapping $\mathrm{K}^{+}$within the membrane domain in the occluded form so that the cation cannot enter or leave (and a similar form is postulated for the hydronium in the outward step of the cycle but is not shown since it is impossible to detect). The $\mathrm{K}^{+}$is then de-occluded, allowing reformation of the $\mathrm{E}_{1}$ form of the enzyme with the ion site now again facing the cytoplasm, and $\mathrm{K}^{+}$is displaced when ATP is bound. The hydronium ion $\left(\mathrm{H}_{3} \mathrm{O}^{+}\right)$is used instead of the naked $\mathrm{H}^{+}$since this enables the necessary hydrogen bonding and is more akin to $\mathrm{Na}^{+}$, which can also be transported by the H,K ATPase at high $\mathrm{pH}$. The above reflects a stoichiometry of $1 \mathrm{H} / 1 \mathrm{~K} / 1 \mathrm{ATP}$. 

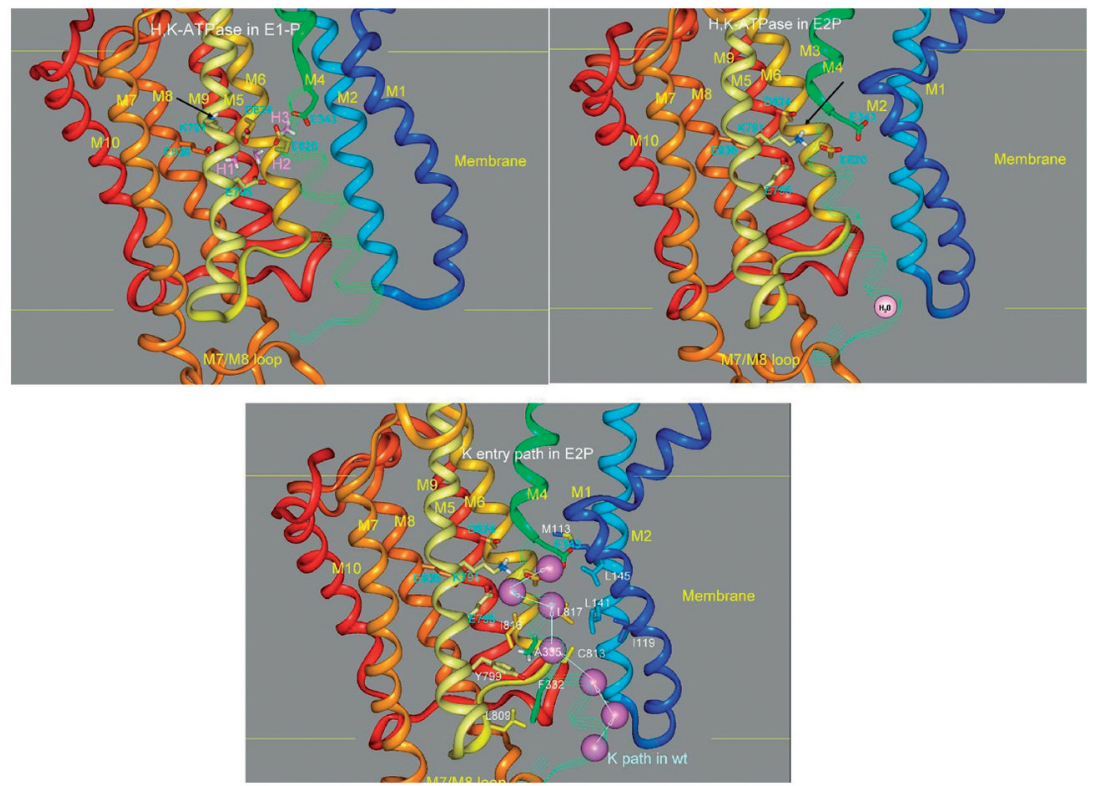

Figure 2.

Ribbon diagrams depicting the ion entry and exit pathways of the gastric H,K ATPase. The left upper image illustrates the conformation of the pump in the $\mathrm{E}_{1} \mathrm{P}$ form. The intramembranal carboxylic acids are shown in stick form and numbered in blue with the arrow highlighting the position of lysine 791, and three hydronium ion-binding sites are shown as $\mathrm{H} 1, \mathrm{H} 2$ and $\mathrm{H} 3$ in pink. The upper right image illustrates the $\mathrm{E}_{2} \mathrm{P}$ conformation where lysine 791 has displaced the second hydronium to exit to the luminal face and the arrow now emphasizes the new orientation of lysine 791 and the exit of $\mathrm{H}_{3} \mathrm{O}^{+}$. The large change in conformation of the first two transmembrane segments on the right of the upperright-hand image generates part of the ion exit and entry pathway. The bottom image illustrates the computed entry path for $\mathrm{K}^{+}$(purple sphere) to displace lysine 791 and take the place of the second hydronium of the upper-left-hand figure, and $\mathrm{K}^{+}$then moves into the position of the third hydronium associated with glutamyl 343 before returning to the cytoplasmic face of the enzyme as shown by images of $\mathrm{K}^{+}$movement into the binding region. E343 has to change orientation to allow cytoplasmic $\mathrm{K}^{+}$exit. 


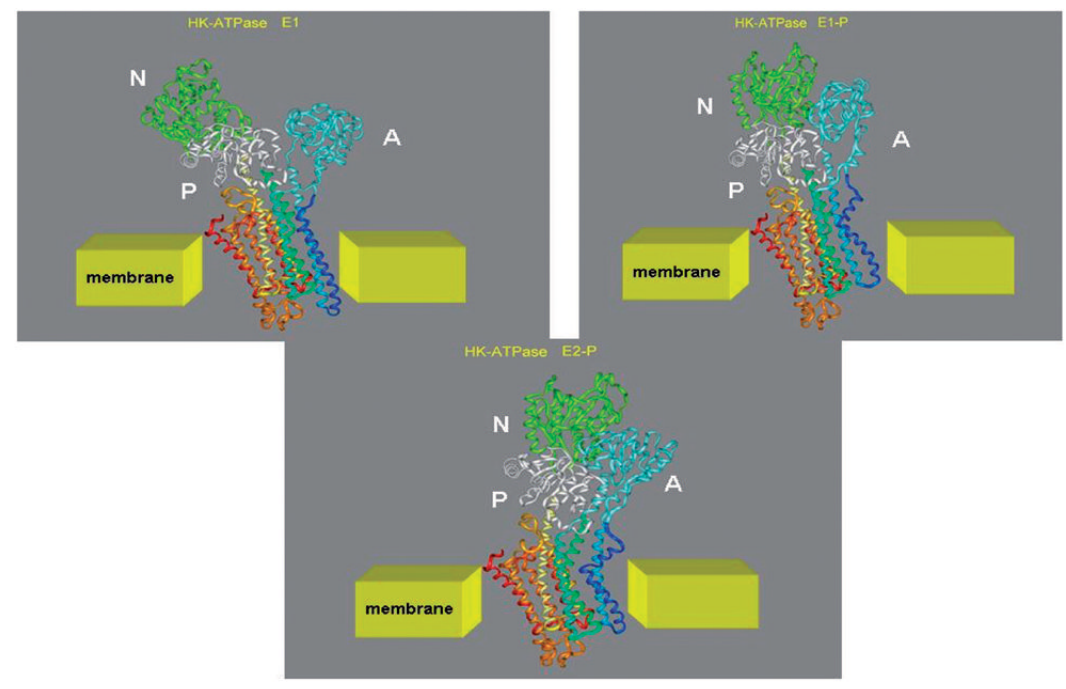

Figure 3.

General changes in orientation and shape of the gastric H,K ATPase in the transition from the E1 to the E2 conformation. On the left are shown the N, P and A domains prior to phosphate transfer from MgATP where the three cytoplasmic domains change conformation. The A, N and P domains are now closer in the E1P form. A further change in the membrane domain with the formation of the E2P form allows expulsion of a proton into the exoplasmic region, followed by $\mathrm{K}^{+}$uptake. Cycling between these general conformations determines the ion transport-catalysis coupling shown in Figures 1 and 2 and determines the functional oligomeric reaction pathway. The arrow shows the luminal vestibule in the $\mathrm{E}_{2}$ conformations that allow docking of the pump inhibitors. 


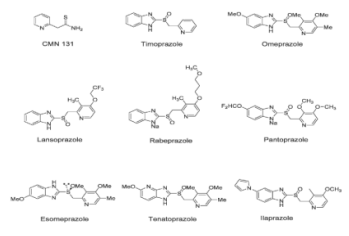

\section{Figure 4.}

The structures of the PPIs. Upper right is CMN131, an acid inhibitory compound which led to the synthesis of timoprazole, the original compound shown to inhibit acid secretion irrespective of the stimulus. Omeprazole was the first PPI introduced for clinical use and was followed by lansoprazole, pantoprazole and rabeprazole. These have very similar halflives of about 60-90 min whereas tenatoprazole, which is under development, has a half-life of about $8 \mathrm{~h}$. They are all prodrugs requiring protonation for conversion into the active species and show differences in their rate of activation and the cysteines of the H,K ATPase that are derivatized. The core structure of all of these is a substituted pyridyl methylsufinyl benzimidazole or pyridyl benzimidazole (tenatoprazole) and ilaprazole, a pyrrole-substituted benzimidazole. Also shown is the $\mathrm{S}$-enantiomer of omeprazole that has a slightly longer plasma half-life than the racemate. 

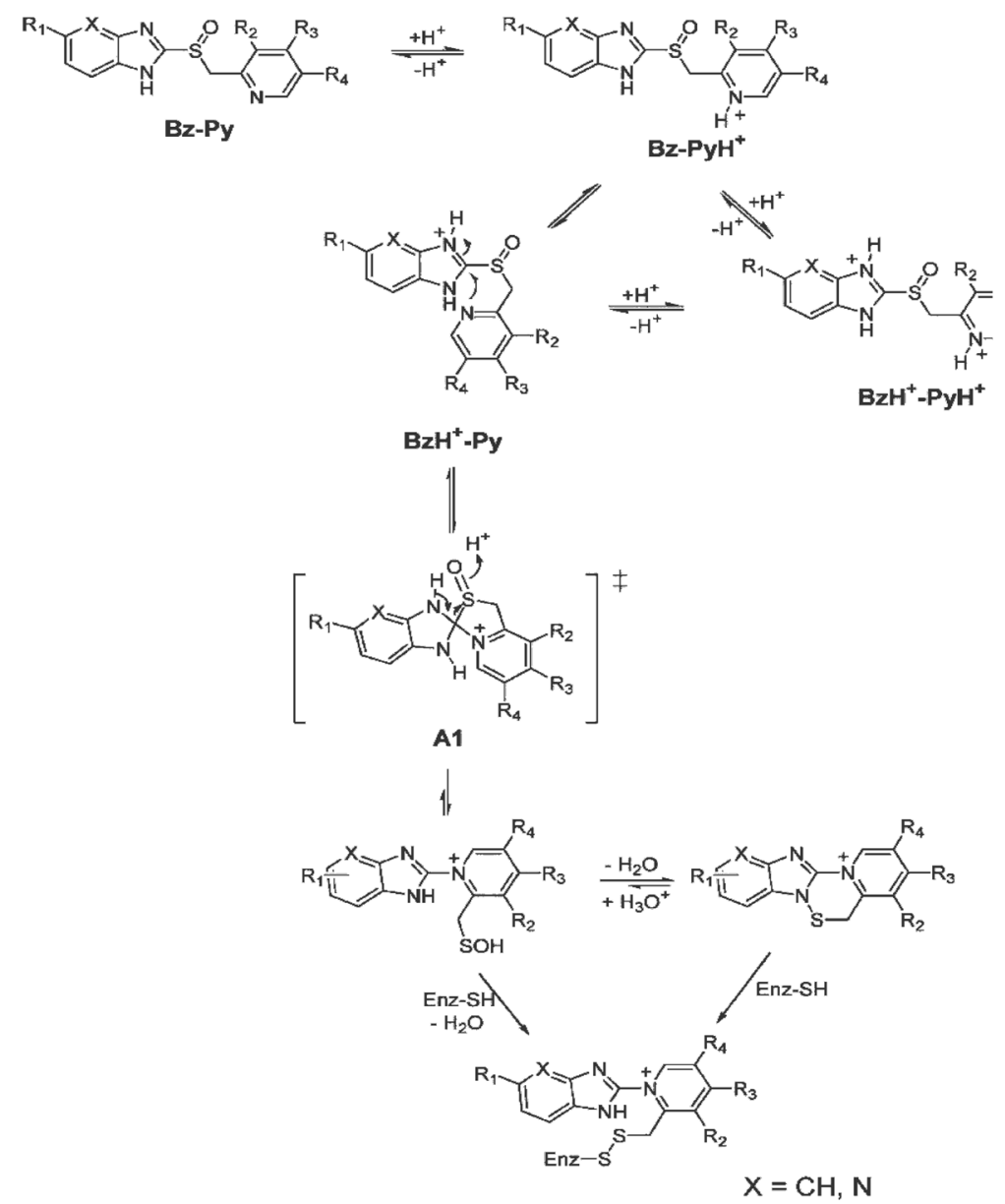

Figure 5.

The mechanism of activation of the PPIs shown in general structural form. The top of the figure shows the protonation of the pyridine ring and the second row of structures shows protonation also of the benzimidazole ring. The bisprotonated form is in equilibrium with the protonated benzimidazole and unprotonated pyridine. In brackets is shown the mechanism of activation whereby the $2 \mathrm{C}$ of the protonated benzimidazole reacts with the unprotonated fraction of the pyridine moiety that results in rearrangement to a permanent cationic tetracyclic sulfenic acid, which in aqueous solute dehydrates to form a cationic sulfenamide. Either of these thiophilic species can react with the enzyme to form disulfides with one or more enzyme cysteines accessible from the luminal surface of the enzyme. 


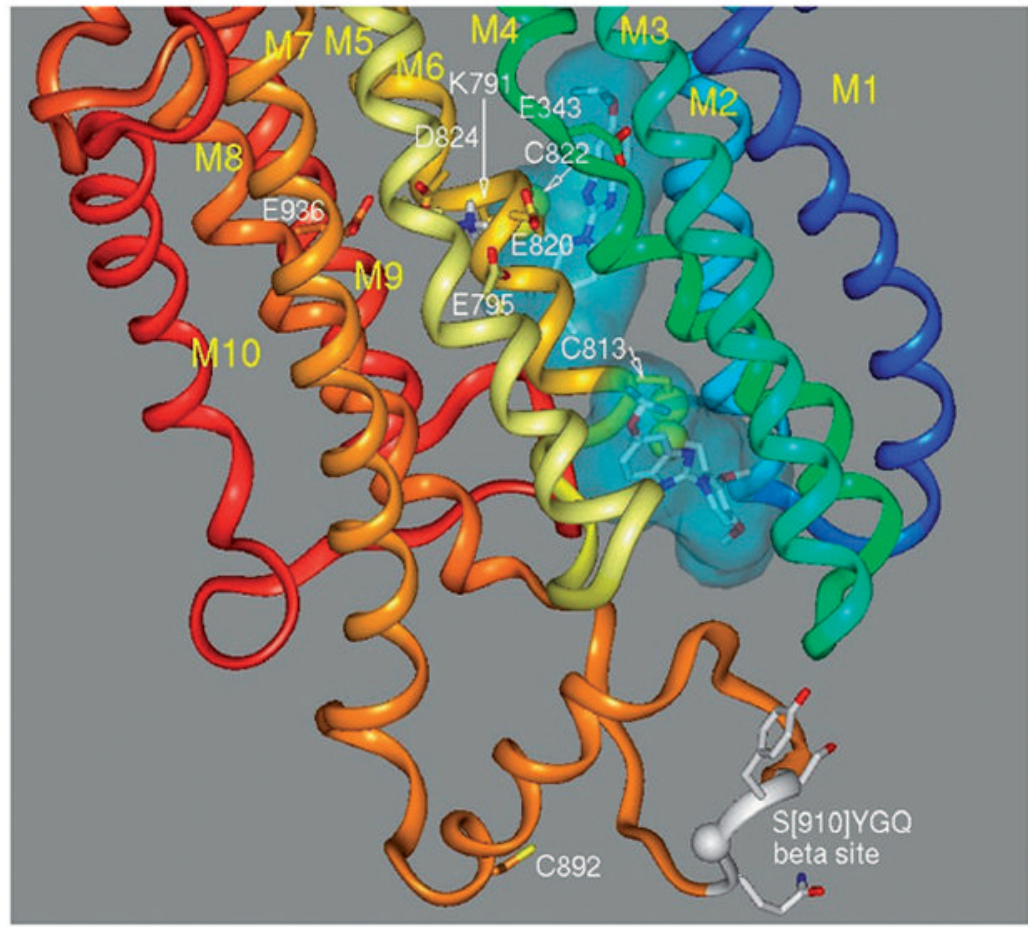

Figure 6.

An illustration of pantoprazole (blue cloud) covalently bound to both cysteine 813 and cysteine 822 (arrows) in the luminal ion access pathway as well as the position of cysteine 892. Binding to either site fixes the enzyme in the $E_{2}$ conformation. The former is in the vestibule facing the lumen and the latter 2.5 turns of the $\alpha$ helix of TM6 into the membrane domain. Also shown in white is the closest contact point of the $\beta$ subunit with the exoplasmic region of the catalytic subunit. The other numbered residues in stick form are the ion-binding domain amino acids. The accessibility of cysteine 813 from the outside face is clearly greater than the accessibility of cysteine 822 . 

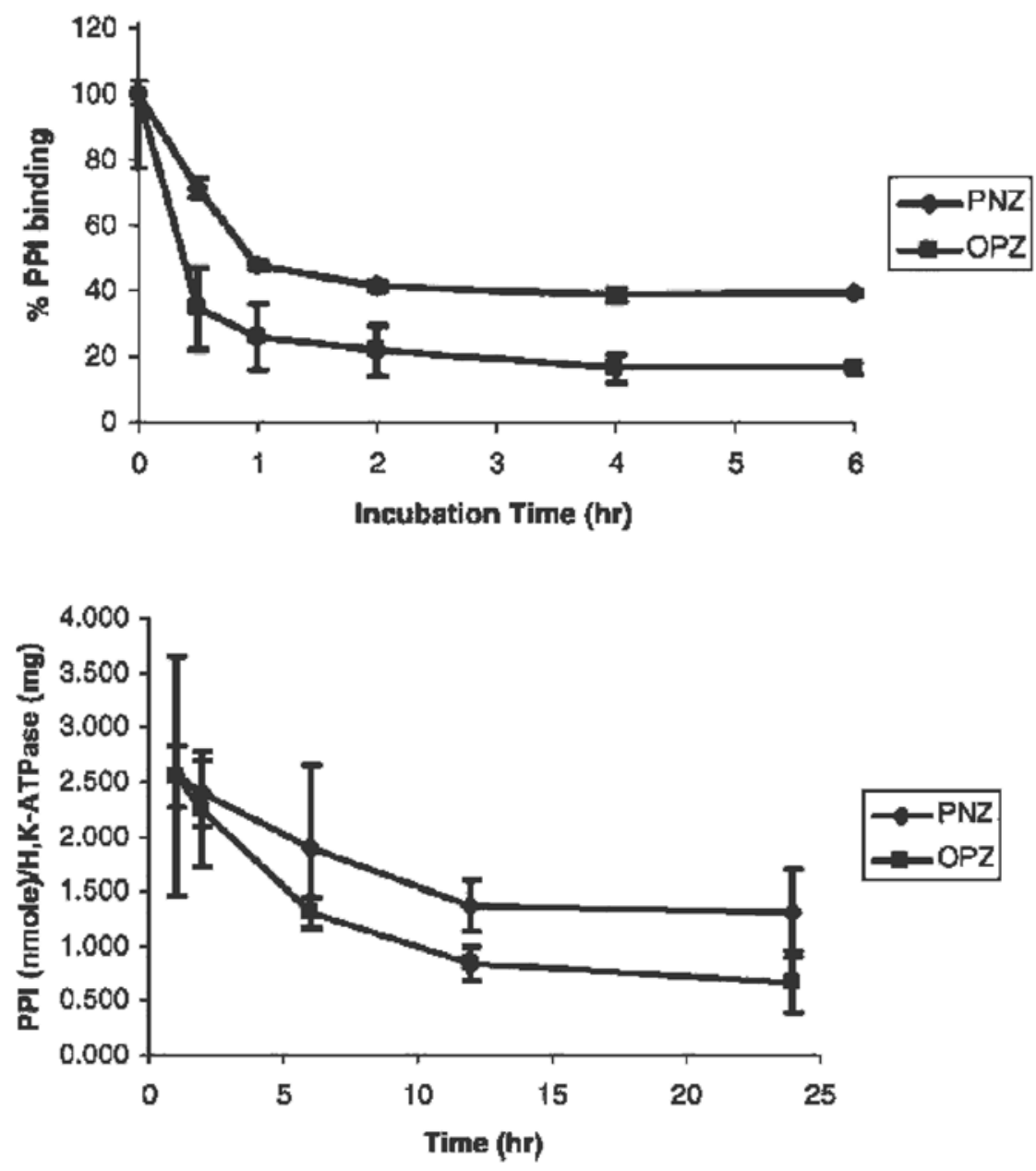

Figure 7.

Upper panel. The rate of loss of bound PPI (PNZ, pantoprazole; OPZ omeprazole) from the in vivo labeled ATPase as a function of time of incubation with $10 \mathrm{mM}$ glutathione. The removal of labeled drug is biphasic; the fast phase accounts for about $84 \%$ of omeprazole binding and $60 \%$ of pantoprazole labeling, whereas the slow phase represents about $16 \%$ of omeprazole labeling and $40 \%$ of pantoprazole labeling. Lower panel. The labeling of the ATPase in vivo as a function of time after intravenous administration of pantoprazole (PNZ) or omeprazole (OPZ). The rate of loss of omeprazole can be seen to be about twice that of pantoprazole and that the stoichiometry of labeling for almost full inhibition of enzyme is about $2.6 \mathrm{nmol}$ drug bound per milligram H,K ATPase. The error bars represent $\pm \mathrm{SE}, \mathrm{n}=4$ animals in each group. 


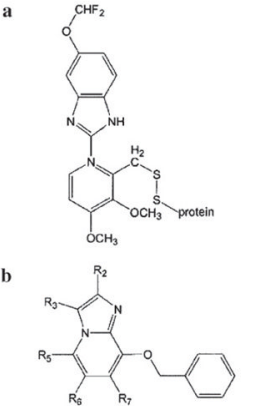

c

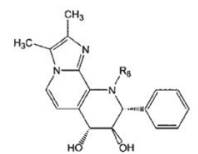

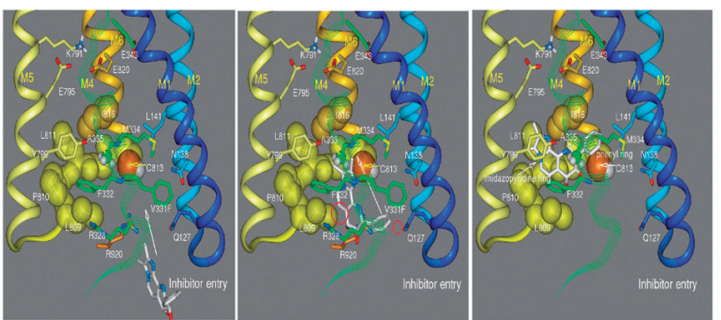

\section{Figure 8.}

Left panel. A comparison of the structure of bound pantoprazole $(a)$ with the core structure of a variety of imidazo[1,2 $\alpha \beta]$ pyridines $(b)$ and a imidazonapthyridine Byk $99(c)$ where the additional ring is orthogonal to the imidazopyridine as is known for the active conformation of SCH28080. Insertion of an Me group at R8 of structure C reduces the affinity of this structure from $\sim 50 \mathrm{nM}$ to $\sim 1 \mathrm{mM}$. Right panel. Different views of the $\mathrm{K}^{+}$competitive inhibitor Byk 36399-binding site from within the plane of the membrane in the first two images. The residues affecting inhibitor binding in TM4 are shown in green, in the TM5/6 loop are shown in yellow and in TM6 in gold. On the far right is shown the docking of the methylated form, Byk 112673, where the affinity is much reduced due to steric hindrance (arrows) with Ala335 and Cys813. The proximity of Cys813, a common binding site for the PPI, to the calculated structure for binding of the APA should be noted. The largest changes in $\mathrm{K}_{\mathrm{i}}$ were generated by the mutants Ala335Cys, Phe331Ile and Leu809Phe. This docking model is also consistent with the binding of an azido derivative of SCH28080 to the region of TM1 and TM2. \{SCH28080, 3-cyanomethyl-2-methyl-8-(phenylmethoxy)imidazo[1,2 $\alpha$ ] pyridine; Byk99, (7R,8R,9R)-7,8-dihydroxy-2,3-dimethyl-9-phenyl-7,8,9,10 tetrahydroimidazo[1,2-h][1,7]-naphthyridine; Byk73, (7R,8R,9R)-7,8-dihydroxy-2,3-dimethyl-9phenyl-10-methyl-7,8,9 trihydro-imidazo[1,2-h][1,7]-naphthyridine. 


\section{Table 1}

pKa values of the PPIs.

\begin{tabular}{llc}
\hline Compounds & $\mathbf{p K}_{\mathbf{a}} \mathbf{1}$ (analytical wavelength) & Estimated $\mathbf{p K}_{\mathbf{a}} \mathbf{2}^{\mathbf{1}}$ \\
\hline Omeprazole & $\mathbf{4 . 0 6} \pm \mathbf{0 . 2 5}(\mathbf{2 5 0 . 5} \mathbf{~ n m})$ & 0.79 \\
Lansoprazole & $\mathbf{3 . 8 3} \pm \mathbf{0 . 1 5}(\mathbf{2 4 0 . 5} \mathbf{~} \mathbf{m})$ & 0.62 \\
Pantoprazole & $\mathbf{3 . 8 3} \pm \mathbf{0 . 2 4}(\mathbf{2 4 7 . 5} \mathbf{~ n m})$ & 0.11 \\
Rabeprazole & $4.53^{2}$ & 0.62 \\
Tenatoprazole & $4.04^{3}$ & -0.12 \\
\hline
\end{tabular}

Bold shows actual measurements, and others are calculated.

${ }^{1} \mathrm{pK}_{\mathrm{a}} 2$ was roughly estimated by adding 'protonated pyridinylme-thylsulfinyl effect' -0.73 to 2-(methylsulfinyl)benzimidazole $\mathrm{pK}_{\mathrm{a}}$.

${ }^{2} \mathrm{pK}_{\mathrm{a}} 1$ was calculated by subtracting $\mathrm{N}$-methylation effect (calculated from lansoprazole $\mathrm{pK}_{\mathrm{a}} 1$ and $\mathrm{N}^{1}$-methyl lansoprazole $\mathrm{pK}_{\mathrm{a}} 1$ ) from $\mathrm{N}^{1}$-methyl rabeprazole $\mathrm{pK}_{\mathrm{a}} 1$.

3

${ }^{3}$ Tenatoprazole $\mathrm{pK}_{\mathrm{a}} 1$ was calculated by subtracting imidazopyridine effect from omeprazole $\mathrm{pK}_{\mathrm{a}} 1$. The imidazopyridine effect on $\mathrm{pK}_{\mathrm{a}}$ was calculated from $\mathrm{N}^{1}$-methyl omeprazole and $\mathrm{N}^{1}$-methyl tenatoprazole. 
Table 2

Some conditions for which intravenous therapy with either $\mathrm{H}_{2} \mathrm{RAs}$ or PPIs should be considered.

\begin{tabular}{ll}
\hline Disease/condition & Target $\mathbf{p H} /$ therapeutic goal \\
\hline GERD & $\begin{array}{l}\text { increased } \mathrm{pH} \\
\text { reduce volume }\end{array}$ \\
Bleeding/rebleeding & abolish acid secretion $\mathrm{pH}$ to $6+$ \\
Stress ulcer prophylaxis & increase $\mathrm{pH}>4.0$ \\
Aspiration pneumonia & $\begin{array}{l}\text { reduce volume } \\
\text { increase } \mathrm{pH}\end{array}$ \\
Zollinger-Ellison syndrome & inhibit acid to $<10 \mathrm{mEq} / \mathrm{H}$ \\
\hline
\end{tabular}

